\title{
RETARDAMENTO DA SECAGEM DE ESPIGAS E QUALIDADE DE SEMENTES DE MILHO (Zea mays L.)
}

\author{
CIRO SCARANARI \\ Engenheiro Agrônomo
}

Orientador: Prof. Dr. Silvio Moure Cicero

\begin{abstract}
Dissertação apresentada à Escola Superior de Agricultura "Luiz de Queiroz", da Universidade de São Paulo, para obtenção do título de Mestre em Agronomia, Área de Concentração: Fitotecnia.
\end{abstract}

\author{
PIRACICABA \\ Estado de São Paulo - Brasil \\ Fevereiro - 1997
}


Dados Internacionais de Catalogaçāo na Publicação (CIP) DIVISÃo DE BIBLIOTECA E DOCUMENTAÇÃO - Campus "Luiz de Queiroz"/USP

Scaranari, Ciro

Retardamento da secagem de espigas e qualidade de sementes de milho (Zea

mays L.) / Ciro Scaranari. - P Piracicaba, 1997.

60 p. : it.

Dissertação (mestrado) - Escola Superior de Agricultura Luiz de Queiroz, 1997.

Bibliografia.

1. Milho 2. Secagem 3. Semente (qualidade) I. Titulo

CDD 633.15

631.56 


\section{RETARDAMENTO DA SECAGEM DE ESPIGAS E QUALIDADE DE SEMENTES DE MILHO (Zea mays L.)}

\section{CIRO SCARANARI}

Aprovada em: 23.04 .97

Comissão julgadora:

Prof. Dr. Silvio Moure Cicero

ESALQ/USP

Prof. Dr. Júlio Marcos Filho

ESALQ/USP

Dr. Paulo Rogério Palma de Oliveira

IZ/Nova Odessa

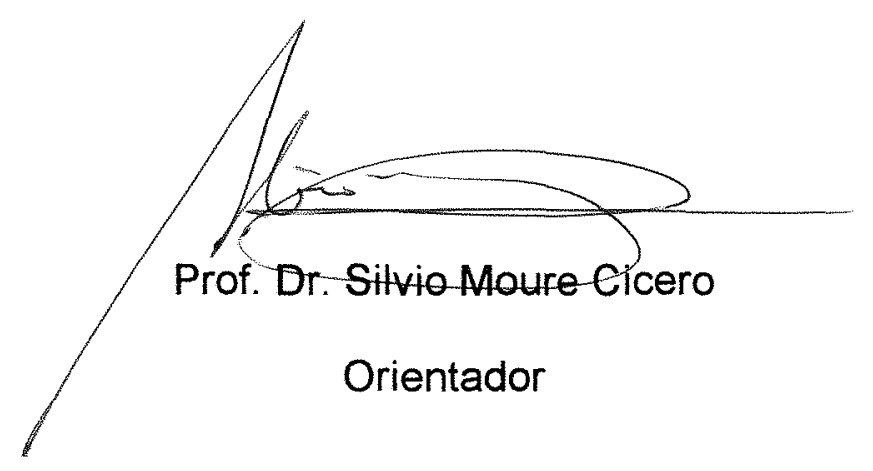


Aos meus pais Hélio José e Marieta, pela minha formação e constantes estímulos

À minha esposa, Maria Christina, pelo

seu amor, incentivo e compreensão

Aos meus filhos, Carolina e

Marcelo, meus maiores amigos

À Deus, pela

oportunidade da vida. 


\section{AGRADECIMENTOS}

Ao Prof. Dr. Silvio Moure Cicero, pela orientação, apoio e amizade.

Ao corpo docente do Departamento de Agricultura da ESALQ/USP, especialmente aos Professores Doutores Walter Rodrigues da Silva, Julio Marcos Filho, Francisco Ferraz de Toledo, Antonio Luiz Fancelli, Geraldo J. A. Dario e Gil Miguel de Souza Câmara, pela atenção e apoio.

À Profa. Dra. Maria Cristina S. Nogueira, do Departamento de Matemática e Estatística da ESALQ/USP e à Dr. ${ }^{a}$ Glaucia Maria Bovi Ambrosano, do Instituto Agronômico de Campinas, pela valiosa colaboração no planejamento e nas análises estatísticas.

Aos Engenheiros Agrônomos Dr ${ }^{\mathrm{a}}$. Ana Dionisia C. L. Novembre e Helena Maria C. P. Chamma, pela eficiência, amizade e colaboração.

Aos funcionários da ESALQ/USP, em especial a llze Helena C. G. das Neves, Maria Aparecida T. Soledade, Carlos Adversi Carlet, João Elias Jabur Filho, João Batista Bigeli e Hodair Luiz Banzatto Junior, pelo apoio, amizade e colaboração.

Aos colegas de curso, em especial a Pedro Abel Vieira Junior, amigo e colaborador, e a Luiz Carlos Miranda, Maria Cristina M. Spinola, Claudio Cavariani, Laura M. Molina Meletti e Leila Martins, pelo companheirismo. 
Aos acadêmicos do Grupo de Experimentação Agrícola, pelo auxílio.

Ao Serviço de Controle de Qualidade do Departamento de sementes, Mudas e Matrizes / CATI, na pessoa da Enga Agra Flavia R. A. Patricio, pela valiosa colaboração na execução dos testes de sanidade.

À empresa São Geraldo - Produção, Comércio e Serviços Ltda. Sementes Semear, na pessoa do $\mathrm{Eng}^{\circ} \mathrm{Agr}^{\circ}$ Sebastião Rezende de Oliveira, pelo apoio na colheita das sementes.

Aos técnicos e funcionários da Gerência Local de Sete Lagoas I EMBRAPA-SPSB, especialmente ao Dr. Paulo Rogério P. de Oliveira, pelas valiosas sugestões, suporte para a execução deste trabalho e irrestrito apoio.

Ao Centro Nacional de Pesquisa de Milho e Sorgo / EMBRAPA, nas pessoas do Dr. Claudinei Andreoli e do técnico Antonio Lucio França Perez pela colaboração e valioso auxilio nas determinações de campo.

Ao Serviço de Produção de Sementes Básicas / EMBRAPA, nas pessoas do funcionário Edison Antonio Bolson, amigo de todos momentos e do colega, conselheiro acadêmico e Gerente Geral, Dr. José Rozalvo Andrigueto, pelo pronto auxílio e suporte para a execução deste trabalho.

À Empresa Brasileira de Pesquisa Agropecuária - EMBRAPA, pela oportunidade de realização do mestrado e pelo suporte financeiro.

A todos que, direta ou indiretamente, contribuíram para a realização do curso. 


\section{ÍNDICE}

Página

Resumo

viii

Summary

$x$

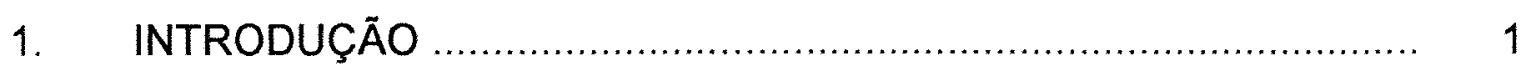

2. REVISÃO DE LITERATURA ............................................. 3

2.1. Maturidade fisiológica, deterioração, vigor e teor de água......... 3

2.2 Efeitos do retardamento de secagem .............................. 10

3. MATERIAL E MÉTODOS ................................................ 14

3.1. Obtenção do material ............................................... 14

3.2. Avaliação da qualidade ............................................. 19

3.2.1. Teor de água ................................................. 19

3.2.2. Teste de germinação ........................................... 19

3.2.3. Teste de envelhecimento acelerado .......................... 20

3.2.4. Teste de emergência em campo ........................... 20

3.2.5. Velocidade de emergência em campo ..................... 20

3.2.6. Teste de frio ................................................... 21

3.2.7. Teste de condutividade elétrica .............................. 21

3.2.8. Teste de sanidade ............................................ 22

3.3. Procedimentos estatísticos .............................................. 23 
4. RESULTADOS E DISCUSSÃO 25

4.1. Grau de umidade das sementes durante o retardamento .......... 25

4.2. Temperatura da massa de espigas durante o retardamento ...... 27

4.3. Evolução da secagem ......................................................... 29

4.4. Avaliação de sanidade das sementes ................................... 32

4.5. Efeitos do retardamento durante o armazenamento ......... 35

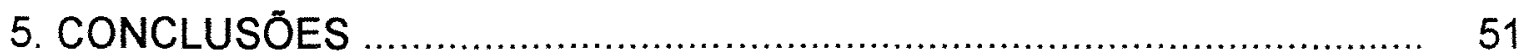

REFERÊNCIAS BIBLIOGRÁFICAS ............................................. 52 


\section{RETARDAMENTO DA SECAGEM DE ESPIGAS E QUALIDADE DE SEMENTES DE MILHO (Zea mays L.)}

Autor: Ciro Scaranari

Orientador: Prof. Dr. Silvio Moure Cicero

\section{RESUMO}

A colheita de sementes de milho em espiga apresenta, entre outras, a vantagem da possibilidade de sua antecipação para momentos mais próximos ao ponto de maturidade fisiológica e de máxima qualidade das sementes.

Entretanto, nesta condição, as sementes encontram-se com elevado teor de água, exigindo cuidados no seu manuseio, notadamente quanto à agilidade no processo de secagem das espigas.

Assim, estudaram-se as consequências do retardamento de até 120 horas ao início do processo de secagem artificial de sementes de milho, cultivar BR 3123, ainda em espigas, com teor inicial de água de $32 \%$ e sob condições ambientes de Sete Lagoas, MG, no mês de agosto de 1995.

Para tanto, foram caracterizados o ar ambiente, o teor de água e a temperatura da massa de espigas durante o período de retardamento de 
secagem, o período de secagem e a qualidade fisiológica das sementes no início, aos 6 meses a aos 12 meses de armazenamento, avaliada através dos testes de germinação, de frio com solo, de envelhecimento artificial, de emergência em campo, de índice de velocidade de emergência e de condutividade elétrica.

Concluiu-se que, sob condições de temperaturas e de umidades relativas moderadas do ar ambiente, o retardamento de até 120 horas ao processo de secagem artificial do milho em espiga, não promove efeitos prejudiciais à qualidade fisiológica das sementes, por até 6 meses de armazenamento. 


\title{
DELAY OF EAR DRYING AND QUALITY OF CORN SEEDS
}

\author{
Author: Ciro Scaranari \\ Adviser: Prof. Dr. Silvio Moure Cicero
}

\section{SUMMARY}

Seed harvesting of ear corn (Zea mays L.), among others, shows an extra advantage for its feasibility of antecipation to moments closer to the physiological maturity and maximum seed quality.

However, under such condition, seeds still possess high moisture content which demands careful handling, specially concerning speed in the ear artificial drying.

The consequences up to 120 -hour delay periods in the ear drying process of corn seeds, cV. BR 3123 , harvested from ears with $32 \%$ moisture content and under environmental conditions of Sete Lagoas, Brazil, in August, 1995, were studied.

Ambient air, moisture content, and temperature of bulk ears during the delaying period of drying and drying time were characterized. Seed quality was evaluated at 0,6 , and 12 months of storage using standard germination, 
accelerated aging, field emergence, speed emergence, electrical conductivity, and cold tests.

Under normal conditions of temperature and relative humidity environment, the delaying ear corn drying process did not affect seed quality, up to a 6-month storage. 


\section{INTRODUÇÃO}

A colheita manual e o manejo de sementes de milho em espigas é uma prática antiga, característica dos primeiros programas de produção de sementes de milho do país.

Com a modernização da agricultura, através de cultivares mais adaptados à colheita mecanizada e do desenvolvimento da indústria de máquinas e implementos agrícolas, esta prática foi abandonada, restringindose apenas aos programas de produção de sementes básicas de híbridos simples, devido a melhores niveis de qualidade física e fisiológica das sementes obtidas.

A adoção do sistema de colheita em espiga apresenta desvantagens em relação ao mecanizado tais como a necessidade de despalha após a colheita manual ou mecânica, esta última problemática em vista do empalhamento mais denso dos cultivares nacionais, e transporte desnecessário de sabugo e água para a usina de beneficiamento de sementes 
Por outro lado apresenta uma série de vantagens, principalmente do ponto de vista da qualidade fisiológica das sementes obtidas, tendo em vista a possibilidade de colheita antecipada, de debulha sob teor mais adequado de água nas sementes, de menores riscos na secagem, uma vez que todo o embrião da semente está protegido pelo sabugo, e da possibilidade de seleção de espigas, onde são eliminadas aquelas com sintomas de deterioração e principalmente as cujo tipo ou padrão diferem visualmente das descritas como características do cultivar em questão.

A adoção do sistema de colheita em espiga, método mais oneroso, tem sido dedicada à produção de materiais considerados de elite ou em fase de lançamento, destinados a consumidores que apresentam maiores investimentos em tecnologia. Nesta categoria encontra-se o cultivar BR 3123 , híbrido triplo, precoce (130 dias), altamente produtivo $e$ destinado a este mercado de consumidores, material utilizado no presente estudo.

A colheita em espigas destes materiais tem se iniciado quando o teor de água das sementes atinge $35 \%$. Nestas condições, é comum a busca de periodos mais breves possiveis entre a colheita e o início do processo de secagem, a fim de se evitar a deterioração e perda da qualidade do produto colhido e exposto ao ambiente.

Assim foram estudados os efeitos do retardamento do início do processo de secagem artificial de sementes de milho híbrido do cultivar BR 3123, ainda em espigas, com o objetivo de verificar possíveis efeitos prejudiciais sobre sua qualidade fisiológica. 


\section{REVISÃO DE LITERATURA}

\subsection{Maturidade fisiológica, deterioração, vigor e teor de água}

Segundo Delouche (1971), a qualidade da semente é produto de sua história, sendo que a qualidade fisiológica é basicamente determinada pela natureza e progresso do processo de deterioração, o qual é mínimo na maturidade fisiológica.

Carvalho \& Nakagawa (1983) conceituam ponto de maturidade fisiológica como sendo o ponto de máxima qualidade fisiológica, isto é, de máxima germinação e vigor, variando entre espécies, entre cultivares de uma mesma espécie e em função de condições de ambiente, sendo este o momento em que há paralisação do transporte de matéria seca para a semente.

As sementes de milho apresentam neste ponto, teor de água entre $30 \%$ e $35 \%$, ponto este que se caracteriza pela formação de uma camada negra na base da semente, interrompendo a conexão nutricional entre a semente e o sabugo, ocasião de peso máximo de matéria seca (Daynard \& Duncan, 1969; Toledo, 1978). A partir daí, o vigor e o poder germinativo das 
sementes decrescem devido aos eventos durante o processo de deterioração (Popinigis, 1977) e em função das condições do ambiente até a colheita, das injúrias mecânicas na colheita e no processamento, dos danos térmicos durante a secagem e também das condições de armazenamento (Abdul-Baki \& Anderson, 1972; McDonald Jr., 1975).

Indicadores visuais como a formação da camada negra e desaparecimento da linha de leite (transição entre o endosperma leitoso e o farináceo) na porção mediana da semente de milho, são, segundo Hunter et al. (1991), indicadores confiáveis de maturidade fisiológica, ponto atingido quando do término da fase de enchimento do grão, verificada com o auxílio do carbono14 como marcador.

A maturidade fisiológica de sementes de milho do cultivar BR 201 Fêmea (híbrido simples, atualmente denominado HS 200, utilizado como parental feminino de diversos híbridos da EMBRAPA, entre eles o BR 3123), produzidas no inverno (mesmo genótipo e mesma época de cultivo utilizada no presente estudo), foi estudada por Borba et al., (1995a), sendo atingida aos 58 dias após o início do florescimento, avaliada através do peso máximo de matéria seca e do aparecimento da camada preta. Os autores citaram que a máxima qualidade, avaliada através do teste de germinação e do teste de envelhecimento artificial, coincidiu com a maturidade fisiológica, podendo inclusive haver antecipações na colheita em até 14 dias sem perdas estatísticas. 
Visando determinar o momento de máxima qualidade de sementes de cevada, Pieta Filho \& Ellis (1992), rejeitaram a hipótese de que a máxima qualidade das sementes coincide com 0 ponto de maturidade fisiológica, e que após este, as sementes começam a se deteriorar. Os autores verificaram que após atingido o máximo peso da matéria seca, o potencial de armazenamento das sementes, estimado pela equação de viabilidade (Ellis \& Roberts, 1980), continuou aumentando, estando seu ponto máximo, 20 e 27 dias após a maturidade fisiológica no primeiro e segundo ano do estudo, respectivamente. Pieta Filho \& Ellis (1991), afirmaram ser improvável que a cevada seja a única cultura em que não se aplica a teoria de máxima qualidade no ponto de maturidade fisiológica. Com efeito, Rao et al. (1991) encontraram máxima qualidade, avaliada igualmente pela equação de viabilidade (Ellis \& Roberts, 1980) 7 dias após a maturidade fisiológica, determinada pelo peso máximo de matéria seca em sementes de milheto (Pennisetum glaucum $\mathrm{R}$. $\mathrm{Br}$.). Por outro lado, Rasyad et al., (1990) encontraram máxima qualidade, estimada pelo teste de envelhecimento acelerado, no ponto de maturidade fisiológica ou pouco antes deste, em 4 cultivares de trigo.

Assim para a maioria das espécies, entre elas o milho, a partir do ponto de maturidade fisiológica se inicia o processo de deterioração da semente que, segundo Delouche (1971) é inexorável e irreversível, cujo progresso depende das adversidades que atuam sobre esta, tais como 
temperaturas extremas, danificação por insetos, ataque de microrganismos, variações no teor de água e outros.

Dentro do processo de deterioração, a semente antes da morte, passa por diversas etapas, as quais são citadas por Delouche (1972) como sendo a degeneração ou degradação das membranas celulares, a degradação dos mecanismos de produção energética, biossíntese e respiração, o decréscimo da atividade enzimática, o aumento dos ácidos graxos livres, danos de cromossomas, a diminuição da velocidade de germinação e do crescimento de plântulas, a redução no potencial de armazenamento das sementes, o atraso e desuniformidade no crescimento e desenvolvimento da planta, a maior sensibilidade às adversidades do meio ambiente, a maior porcentagem de plântulas anormais, e finalmente, perda do poder germinativo.

Muito embora esses sintomas de deterioração, anteriores à morte da semente estejam bem estabelecidos, suas causas ainda não são claras, devido ao número relevante de alterações citológicas e metabólicas detectadas, o que torna difícil o estabelecimento das primeiras causas na cadeia de deterioração ou da identificação de causa e efeito de uma resposta deteriorativa específica (Roberts, 1973).

Três grupos de teorias foram desenvolvidas por fisiologistas para explicar as causas bioquimicas e fisiológicas da deterioração (McGee, 1983):

a) relativas à acumulação de produtos deletérios do metabolismo, resultantes da inativação de enzimas e ácidos nucleicos e de membranas não funcionais; 
b) redução da eficiência de organelas, células e órgãos, com o seu uso crescente; c) aumento da taxa de mutações, com o avanço da idade dos tecidos, levando a um processo metabólico deficiente.

Segundo Roos (1986), as teorias sobre a razão da perda de viabilidade das sementes se resumem em : a) redução das reservas nutricionais; b) alteração da composição química; c) alteração do sistema de membranas; d) alterações nas atividades enzimáticas e; e) danificações genéticas por mutações.

Os mecanismos pelos quais as sementes se deterioram não são conhecidos; porém a idéia comum é que sementes deterioradas apresentam baixa habilidade para incorporar vários substratos como polissacarideos, proteínas e ácidos nucleicos (Anderson \& Gupta, 1986). Os autores sugeriram pesquisas em sementes nos primeiros estágios de deterioração, antes da perda de viabilidade, utilizando modernas e sofisticadas técnicas para avaliação do sistema de membranas e biologia molecular.

Roberts (1986), comentou que tão logo as sementes estejam maduras na planta-mãe, começam a deteriorar-se segundo taxas que dependem das condições do ambiente. Ainda segundo o autor, há inúmeros sintomas de deterioração, mas a maioria se resume na perda da integridade das membranas celulares, em mudanças na estrutura molecular dos ácidos nucleicos e na redução da atividade de enzimas, levando à redução na 
velocidade de germinação e do crescimento de plântulas e na habilidade para germinar sob condições de estresse, sindrome descrita como baixo vigor.

Para avaliar os níveis de deterioração da semente, é necessária a aplicação de diversos testes de vigor, uma vez que segundo Popinigis (1975), o teste de germinação não é capaz de predizer o potencial de estabelecimento de uma plântula no campo, sendo alguns destes testes: velocidade de emergência no campo, estande final, peso fresco e peso seco de plântulas, primeira contagem de germinação, envelhecimento acelerado, condutividade elétrica, entre outros.

Para Welch \& Delouche (1967), o alto teor de água da semente é provavelmente a principal causa da perda de viabilidade e vigor.

Matthes et al.(1969), afirmaram que a colheita antecipada de sementes reduz os danos que ocorrem no campo devido à incidência de doenças, ao ataque de pragas e à condições climáticas adversas, recomendando que para regiões de clima tropical e subtropical, as sementes de milho sejam colhidas com teores de água entre $25 \%$ e $35 \%$ para serem, em seguida, secadas artificialmente até nível adequado para preservação da qualidade fisiológica durante o armazenamento, que segundo Delouche et al.(1973), deve ser de $12 \%$ ou menos.

Segundo Villela (1991), a permanência das sementes com elevado teor de água durante o período compreendido entre a colheita e a secagem, contribui para acelerar o processo de deterioração devido a elevada 
atividade metabólica que, além de consumir parte das substâncias de reserva, libera energia e água, favorecendo o desenvolvimento de microrganismos e insetos.

Para Gregg \& Fagundes (1977), o teor de água exerce influência acentuada e direta no metabolismo da semente, sendo que na faixa de $18 \%$ a $40 \%$ encontram-se fisiologicamente maduras, com alta taxa de respiração, altamente susceptíveis à deterioração no campo, e com presença acentuada de insetos e microrganismos;

Segundo diversos autores, citados por Carvalho (1992), a velocidade de deterioração de sementes de milho durante o armazenamento é influenciada por fatores dos quais os mais importantes parecem ser a umidade do ambiente e a temperatura do ar, a taxa de crescimento de patógenos existentes, a localização e a severidade dos danos mecânicos, a condição fisiológica inicial das sementes, as características genéticas do cultivar, o armazenamento e as flutuações das condições de umidade relativa e de temperatura ambiente. Citaram ainda que a temperatura e a umidade relativa do ar durante o armazenamento são os fatores mais importantes na conservação das sementes.

Quando as sementes são expostas a um ambiente com determinada umidade relativa do ar, há tendência deste ceder água para a semente, ou esta para $\circ$ ar, até que seja atingido o ponto de equilíbrio higroscópico (Toledo \& Marcos Filho, 1977). 
Assim, o ponto de equilíbrio higroscópico das sementes varia em função do ambiente ao qual estão submetidas $e$, em sementes de milho, segundo Carvalho \& Nakagawa (1983), sob temperatura constante de $25^{\circ} \mathrm{C}$ e umidade relativa do ar ambiente de $15 \%, 30 \%, 45 \%, 60 \%, 75 \%, 90 \%$ e $100 \%$, apresentam teor de água de $6,4 \% ; 8,4 \% ; 10,5 \% ; 12,9 \% ; 14,8 \% ; 19,1 \%$ e $23,8 \%$, respectivamente.

\subsection{Efeitos do retardamento de secagem}

Sttele et al. (1969) verificaram que sementes de milho com $25 \%$ de teor de água, sob $23,9^{\circ} \mathrm{C}$ de temperatura da massa de sementes e $30 \%$ de nível de dano mecânico, alcançam um período permissível sem perda de qualidade de apenas 5 dias (120 horas).

Muñoz \& Arboleda (1976) estudando o retardamento de secagem de sementes de milho em espiga, colhidas com teores de água de $43 \%$ e $37 \%$, por períodos de 0 a 3 dias, verificaram que não houve prejuizos sobre a viabilidade das sementes, estando todos os tratamentos com germinação superior a $95 \%$ até 8 meses de armazenamento em condições ambientes de Palmira, Colombia.

Borba et al. (1995b) trabalhando com sementes debulhadas de milho da cultivar BR 205 com teores de água de $16 \%$ e $21 \%$, estudaram os efeitos do retardamento da secagem sobre as sementes armazenadas em 
tambores metálicos por periodo de 0 a 156 horas; e concluíram que para a obtenção de sementes com germinação acima do padrão mínimo de $85 \%$, a secagem pode ser retardada por um período de 156 e 85 horas, para teores de água das sementes de $16 \%$ e $21 \%$ respectivamente. Quanto ao vigor (teste de envelhecimento acelerado), concluíram que a queda foi linear, variando de $83,6 \%$ (para 0 horas) a $65,0 \%$ (para 156 horas), ficando evidente que quanto maior o período de retardamento da secagem, maiores foram as perdas no vigor.

Os efeitos do retardamento de secagem sobre a qualidade de sementes de milho até aqui citados, foram os únicos encontrados na literatura disponível, o que reforça as justificativas da realização do presente trabalho. Contudo, vários autores estudaram tais efeitos sobre a qualidade de sementes de outras espécies, os quais são citados a seguir:

Andrigueto (1975) trabalhando com sementes úmidas de trigo, constatou que a qualidade fisiológica é afetada adversamente pelo retardamento da secagem, sendo que o tempo máximo possível para o armazenamento da semente nas condições de Pelotas, RS, foi de 60 horas para sementes com $20,9 \%$ de água, 108 horas para sementes com $18,1 \%$ e 144 horas para sementes com $14,7 \%$. Constatou ainda que as perdas imediatas de vigor somente se evidenciaram em sementes com $20,9 \%$ de água, e os efeitos latentes, a partir do $4^{\circ}$ mês de armazenamento para as sementes nos três teores de água. 
Cerqueira et al. (1979) estudando os efeitos do retardamento de secagem em sementes de soja, também em Pelotas, RS, verificaram que 0 retardamento de até 240 horas sob $19,1 \%$ de água não produziu reduções imediatas na qualidade fisiológica das sementes, o que veio a ocorrer após 3 meses de armazenamento, depois de 72 horas de retardamento.

Rush (1985) estudando o comportamento de sementes de soja submetidas a retardamento de colheita associado a retardamento de secagem nas condições de Jaboticabal, SP, concluiu com relação ao segundo parâmetro, que os efeitos do retardamento de secagem sob teores de água variando de $15,3 \%$ a $21,8 \%$, se manifestaram negativamente sobre a qualidade fisiológica das sementes já a partir de 24 horas, sendo que este período variou conforme o teste de vigor aplicado (primeira contagem de germinação em 72 horas, índice de velocidade de emergência em 24 horas, comprimento de hipocótilo e peso de matéria seca em 48 horas).

Ainda em sementes de soja, França Neto et al. (1984), estudaram os efeitos do retardamento do início da secagem sobre a qualidade fisiológica e sanitária, utilizando sementes com 3 graus de umidade $(19,2 \%, 14,6 \% 12,0 \%)$, armazenadas em tambores metálicos em períodos de 0 a 6 dias. $\mathrm{Na}$ avaliação da qualidade fisiológica (germinação e envelhecimento acelerado), observaram acentuada queda para o nível de $19,2 \%$, em menor intensidade para o teor de $14,6 \%$ e sem efeito para o nível de $12,0 \%$. No armazenamento verificaram efeitos no maior nível a partir do segundo dia de retardamento. 
Em arroz, Valle (1978) trabalhou com sementes do cultivar Bluebelle com teor de água de $20 \%$, para avaliar os efeitos do retardamento da secagem sobre sua qualidade fisiológica e observou que a qualidade da semente foi rápida e adversamente afetada quanto mais se retardava 0 processo de secagem (após 24 horas o processo de deterioração já se evidencia e após 72 horas seu efeito foi drástico). Após secas e armazenadas por 6 meses em condições ambientais de Pelotas, RS, concluiu que a partir de 24 horas de retardamento, as sementes têm sua qualidade fisiológica afetada.

Martinelli (1985) trabalhando com sementes de sorgo sacarino BR 503, concluiu que o retardamento da secagem acarreta uma redução contínua na qualidade fisiológica das sementes. Os graus iniciais de umidade estudados foram de $20,4 \%, 19,3 \%, 18,5 \%$ e menor que $18 \%$ e a partir de $40,48,72$ e 120 horas respectivamente, as sementes tiveram sua qualidade fisiológica afetada. 


\section{MATERIAL E MÉTODOS}

\subsection{Obtenção do material}

Esta fase envolveu a obtenção das sementes e foi levada a efeito durante o mês de agosto de 1995. Para tanto foram utilizadas espigas provenientes das linhas femininas (híbrido simples BR 201-Fêmea) de campo de produção de sementes híbridas de milho do cultivar BR 3123, produzidas na safra 1994/95 pela empresa São Geraldo - Produção, Comércio e Serviços Ltda. - Sementes Semear (franqueada do Programa de Híbridos de Milho da EMBRAPA), no município de Santo Hipólito, Estado de Minas Gerais.

A colheita foi efetuada em 28/08/95, 79 dias após o início do florescimento, quando as sementes apresentavam-se fisiologicamente maduras, fato constatado pela presença da camada preta na base das sementes, momento este em que encontravam-se com 35\% de água. Assim foram colhidas e despalhadas manualmente, aproximadamente 9.000 espigas, em 3 repetições de cerca de 3.000 espigas cada e acondicionadas em 3 "containers" tipo "bag", de polipropileno trançado, com volume de carga de 1 $m^{3}$. 
Após completados, e no mesmo dia, os "bags" foram transportados por via rodoviária até a usina de beneficiamento de sementes (UBS) da Gerência Local de Sete Lagoas, MG, unidade do Serviço de Produção de Sementes Básicas - SPSB / EMBRAPA, distante $180 \mathrm{~km}$ do local de produção, após o pôr do sol e sem enlonamento, condição esta na qual são transportadas usualmente grande parte das sementes de milho em espigas pelas empresas do setor.

Ao chegar, os 3 "bags" foram depositados abertos, em área coberta da UBS, sob ambiente natural e com monitoramento da temperatura da massa de espigas e das condições de temperatura e de umidade relativa do ar ambiente, tendo sido determinado o grau de umidade das sementes no momento da chegada, realizado pelo método de estufa a $105^{\circ} \mathrm{C} \pm 3^{\circ} \mathrm{C}$.

Assim, os "bags" se constituíram nos blocos do experimento, de onde foram coletadas parcelas com 30 espigas cada, distribuídas no tempo, às $16,24,32,40,48,56,64,72,80,88,96,104,112$ e 120 horas após a chegada. Estas parcelas, se constituíram nos 14 tratamentos do experimento, a partir das quais foram obtidas todas as informações envolvendo o presente estudo.

Devido à prevista dificuldade na coleta de amostras de milho em espigas, no momento do enchimento de cada "bag" ainda no campo, foram distribuídas aleatoriamente cerca de 500 espigas, embaladas 2 a 2 em pequenos sacos de malha aberta, de polipropileno, semelhantes àqueles utilizados para acondicionamento de frutas em supermercados, presos por 
cordões, também de polipropileno, para facilitar a sua retirada da massa de espigas. Este sistema foi idealizado de maneira a facilitar a retirada e reduzir o risco de interferência no ambiente da massa de espigas, no momento da coleta de amostras.

Este volume de 500 espigas foi calculado como sendo suficiente para todas as determinações e avaliações necessárias e representou $16,3 \%$ da população de cada "bag", calculado como segue:

- peso de recepção: 1220 kg ou média de 406,6 kg/"bag";

- peso médio de cada espiga: $0,133 \mathrm{~kg}$;

- população média de cada "bag": 3057 espigas;

- utilização: 500 : $3057=16,3 \%$.

Imediatamente após cada coleta, determinou-se o grau de umidade das sementes através de método indireto, com a utilização de determinador Universal, previamente calibrado com o método de estufa a $105^{\circ} \mathrm{C} \pm 3^{\circ} \mathrm{C}$, sendo as parcelas submetidas à processo de secagem em secador estacionário para milho em espigas, marca D'Andrea, distribuindo-se ao acaso cada parcela de 30 espigas sobre o fundo perfurado, isolando-se umas das outras, e em camada única de espigas.

A secagem estacionária foi executada com fluxo infra-insuflado e com fornecimento contínuo de calor, cuja temperatura, tomada logo acima da camada de espigas, nunca foi superior a $35^{\circ} \mathrm{C}$. 
Visando-se o conhecimento da curva de secagem, procedeu-se à coleta extra de espigas especificamente para este fim, determinando-se o grau de umidade das sementes a cada 24 horas, também através de determinador Universal.

Igualmente, o acompanhamento da perda de água das sementes de cada parcela foi efetuado através do determinador Universal, método este adotado tendo em vista a necessidade de resposta imediata, bem como em função do grande número de amostras envolvidas.

A decisão quanto ao término da secagem foi baseada nos resultados obtidos, sempre que atingidos aproximadamente $14 \%$, equivalentes por aferição anterior a $12 \%$, obtidos através do método de estufa a $105^{\circ} \mathrm{C} \pm$ $3^{\circ} \mathrm{C}$

Assim ao atingirem o citado grau de umidade (14\% no determinador Universal), as parcelas foram retiradas do secador, tendo sido suas espigas debulhadas em debulhador manual de parcelas, evitando-se ao máximo que não fossem causados danos às sementes.

Após a debulha, as sementes de cada parcela (tratamentos), permaneceram acondicionadas em sacos de papel kraft e em ambiente aberto até o término da secagem do último tratamento, após o que foram levadas para câmara regulada a $10^{\circ} \mathrm{C}$ e $45 \%$ de umidade relativa do ar, por um período de 7 dias, para uniformização do teor de água das sementes. 
Vencido este período, as sementes foram submetidas a processo de separação por espessura, com auxílio de peneira de crivos oblongos de 14/64" x 3/4", agitada manualmente, descartando-se a fração retida. Em seguida, para a separação por largura, repetiu-se o processo com o uso de peneira de crivos circulares de 18/64".

As sementes retidas nesta última peneira, de espessura inferior a $14 / 64$ " e de largura superior a 18/64" (faixa que contém todas as classes de tamanho ditas comerciais de sementes de milho) sofreram processo de seleção visual para eliminação de grãos podres, ardidos e chochos, após o que reduziu-se para peso de $2 \mathrm{~kg}$ por parcela, ficando assim constituídas as amostras de trabalho. Em seguida foram submetidas a tratamento químico com fungicida e inseticida na dosagem de 10 litros de solução (1600 g de Captan $750 \mathrm{TS}, 30 \mathrm{ml}$ de Actelic $50 \mathrm{CE}, 8 \mathrm{ml}$ de espalhante adesivo Extravon, $400 \mathrm{ml}$ de corante Verde Basonyl e água) por tonelada. O excedente aos $2 \mathrm{~kg}$ de sementes não tratadas, foi separado para condução de testes de sanidade, mais adiante descrito.

As sementes tratadas, embaladas em sacos de papel kraft e devidamente identificadas, foram mantidas agrupadas por bloco em uma única embalagem de papel multifoliado ( 4 folhas), idêntica àquelas para acondicionar $40 \mathrm{~kg}$ de sementes, para cada bloco e transferidas para armazém anexo à UBS, sem controles especiais das condições de ambiente, permanecendo nesta condição por um periodo de 12 meses. A partir do $4^{\circ}$ mês, passaram a 
ser submetidas a expurgo com fosfeto de alumínio, na proporção de 5 pastilhas do produto comercial Gastoxin por tonelada de sementes, repetindo-se a operação a cada 15 dias.

\subsection{Avaliação da qualidade}

No período de setembro/95 a agosto/96 (no início, aos 6 meses e aos 12 meses de armazenamento) as sementes de cada tratamento foram submetidas aos seguintes testes, com o objetivo de se verificar efeitos imediatos, referentes ao início do armazenamento, e efeitos latentes, referentes aos 2 últimos períodos:

3.2.1. determinação do teor de água (\%): conduzido em estufa elétrica marca Fanem, de desidratação sem ventilação forçada, utilizando o método de estufa a $105^{\circ} \mathrm{C} \pm 3^{\circ} \mathrm{C}$, durante 24 horas, conforme metodologia descrita nas Regras para Análise de Sementes (Brasil, 1992);

3.2.2. teste de germinação (\%): conduzido em germinador marca De Leo, tipo Mangelsdorf, em rolo de papel toalha a $27^{\circ} \mathrm{C}$ em 8 repetições (subamostras) de 50 sementes / parcela, seguindo-se as demais recomendações contidas em Brasil (1992); 
3.2.3. teste de envelhecimento acelerado (\%): conduzido em estufa incubadora para B.O.D., marca Eletrolab, baseando-se em metodologia descrita por Marcos Filho (1994), e consistiu na utilização de caixas gerbox como compartimento individual (mini-câmaras) possuindo no seu interior, bandeja de tela de aço inox, sobre a qual foram distribuídas pouco mais de 200 sementes, mantendo-se as mini-câmaras a $41,7^{\circ} \mathrm{C}$ após a adição de $40 \mathrm{ml}$ de água destilada em seu interior, por período de 96 horas. Vencido este período, as sementes foram submetidas ao teste de germinação, como descrito em 3.2.2., porém em 4 repetições de 50 sementes e com interpretação aos 5 dias após a instalação;

3.2.4. teste de emergência (\%) das plântulas em campo: realizado em canteiro contendo solo cultivado com milho, de dimensões de $1 \mathrm{~m} \times 10 \mathrm{~m}$, com irrigação suplementar à precipitação pluvial, com 2 repetições (subamostras) de 50 sementes / parcela, semeadas a $5 \mathrm{~cm}$ de profundidade, em linhas de $1 \mathrm{~m}$, espaçadas a $10 \mathrm{~cm}$ entre si, com avaliação aos 14 dias após a semeadura, considerando-se as plântulas emersas presentes.

3.2.5. velocidade de emergência das plântulas em campo: obtido conjuntamente com 0 teste de emergência das plântulas (3.2.4.), por meio de contagens diárias das plântulas emersas a partir do $4^{\circ}$ dia e até 
- $10^{\circ}$ dia após a semeadura. O índice de velocidade de emergência (IVE) foi calculado utilizando-se fórmula proposta por Maguire (1962):

$$
\text { IVE }=N_{1} / D_{1}+N_{2} / D_{2}+N_{3} / D_{3}+\ldots .+N_{n} / D_{n} \quad \text { onde: }
$$

$N_{1}, N_{2}, N_{3}, \ldots \ldots, N_{n}=n^{o}$ de plântulas emergidas na $1^{a}, 2^{a}, 3^{a}, \ldots$. e última contagem, respectivamente;

$D_{1}, D_{2}, D_{3}, \ldots \ldots, D_{n}=n^{\circ}$ de dias da semeadura à $1^{a}, 2^{a}, 3^{a}, \ldots$ e última contagem, respectivamente;

3.2.6. teste de frio (\%): conduzido com 4 repetições (sub-amostras) de 50 sementes / parcela, distribuídas à profundidade de $2-3 \mathrm{~cm}$ em caixas plásticas contendo substrato composto de mistura areia/solo na proporção de 3:1, umedecido com água equivalente a $60 \%$ da capacidade de retenção da mistura. Uma vez tampadas, as caixas foram mantidas em câmara regulada a $10^{\circ} \mathrm{C}$ por 7 dias sendo em seguida retiradas e mantidas a temperatura ambiente por igual período, procedendo-se então à contagem do número de plântulas emersas (Cicero \& Vieira, 1994);

3.2.7. teste de condutividade elétrica: conduzido seguindo-se metodologia proposta por Marcos Filho et al. (1987), com 4 repetições (sub-amostras) de 25 sementes aparentemente íntegras por parcela, com peso previamente determinado, colocadas sob embebição em recipientes 
plásticos contendo $75 \mathrm{ml}$ de água destilada por 24 horas à temperatura constante de $25^{\circ} \mathrm{C}$, seguindo-se agitação e leitura em condutivímetro marca Digimed, modelo CD 20, previamente calibrado com solução padrão de cloreto de potássio $\left(146,7 \mu\right.$ mhos a $\left.25^{\circ} \mathrm{C}\right)$, calculando-se os valores obtidos para $\mu \mathrm{mhos} / \mathrm{cm} / \mathrm{g}$;

3.2.8. teste de sanidade: realizado apenas no início do armazenamento e com sementes sem tratamento químico, utilizando-se o método de papel de filtro com congelamento, descrito por Menten (1988), conduzido com 4 repetições (sub-amostras) de 50 sementes / parcela, semeadas em placas plásticas de Petri de $9 \mathrm{~cm}$ de diâmetro, contendo 3 folhas de papel de filtro umedecidas, permanecendo sob incubação à temperatura de $20^{\circ} \mathrm{C} \pm 2^{\circ} \mathrm{C}$, sob regime de 12 horas de escuro e 12 horas de luz com comprimento de onda próximo ao ultravioleta. Vencido este período, as placas foram submetidas à refrigeração a $-18^{\circ} \mathrm{C}$ por 24 horas, retornando à incubação por mais 5 dias, quando procedeu-se à avaliação mediante a determinação e identidade dos microrganismos presentes nas sementes, com auxílio de microscópio estereoscópico.

Os testes e determinações citadas (3.2.1. a 3.2.8.) foram conduzidas no Laboratório de Análise de Sementes da Gerência Local de Sete Lagoas / SPSB I EMBRAPA em Sete Lagoas, MG (3.2.1. a 3.2.3.), no Laboratório de Análise 
de Sementes do Centro Nacional de Pesquisa de Milho e Sorgo / EMBRAPA em Sete Lagoas, MG (3.2.4. e 3.2.5.), no Laboratório de Análise de Sementes do Departamento de Agricultura da Escola Superior de Agricultura "Luiz de Queiroz" em Piracicaba, SP (3.2.6. e 3.2.7.) e no Serviço de Controle de Qualidade do Departamento de Sementes, Mudas e Matrizes / CATI em Campinas, SP (3.2.8.).

\subsection{Procedimentos estatísticos}

O presente trabalho foi conduzido sob o delineamento de blocos casualizados completos com parcelas subdivididas, cujo esquema da análise da variância encontra-se na Tabela 1.

Tabela 1. Esquema da análise de variância conjunta dos dados de qualidade fisiológica para tempo de espera de secagem e época de armazenamento.

\begin{tabular}{lc}
\hline \hline Causas da variação & Graus de liberdade \\
\hline \hline Tempo (T) & 13 \\
Blocos $(B)$ & 2 \\
Resíduo A & 26 \\
\hline Parcelas & 41 \\
\hline Epoca (E) & 2 \\
Interação T XE & 26 \\
Resíduo B & 56 \\
\hline \hline Total & 125 \\
\hline \hline
\end{tabular}


A análise dos dados foi efetuada através do programa estatístico SAS e para o estudo sobre as consequências provocadas às sementes, considerou-se separadamente o efeito do tempo de retardamento de secagem dentro de cada época. Constatadas diferenças significativas através da aplicação do Teste " $F$ " ao nível de $5 \%$ de probabilidade, aplicou-se a análise de regressão polinomial de $1^{\circ}$ e de $2^{\circ}$ graus, uma vez que se trata de série temporal, portanto com níveis dependentes entre si (Gomes, 1990).

Não foram analisados estatisticamente os dados referentes à análise de sanidade, uma vez que foram obtidos a partir de parcelas não submetidas a tratamento fungicida, portanto diferenciadas das demais, e que teve como objetivo constatar a presença e o comportamento da população de patógenos durante o período de retardamento de secagem.

Também não foram analisados estatisticamente os dados do teor de água, utilizados no monitoramento do comportamento biológico das sementes durante o período de retardamento de secagem, da própria secagem e na avaliação da qualidade das sementes. 


\section{RESULTADOS E DISCUSSÃO}

\subsection{Grau de umidade das sementes durante o retardamento}

Os dados do ar ambiente durante o retardamento de secagem encontram-se na Tabela 2 e referem-se ao período de 29/8 a 2/9/95, época em que habitualmente as condições locais do ar ambiente apontam valores baixos de umidade relativa e temperaturas amenas.

Tabela 2. Condições do ar ambiente durante o período de retardamento de secagem. Sete Lagoas - MG, 1995.

\begin{tabular}{cccccccc}
\hline Dia & \multicolumn{3}{c}{${\text { Temperatura }\left({ }^{\circ} \mathrm{C}\right)}$} & \multicolumn{4}{c}{ Umidade Relativa (\%) } \\
\cline { 2 - 8 } & max. & min. & média $^{(1)}$ & $9 \mathrm{~h}$ & $15 \mathrm{~h}$ & $21 \mathrm{~h}$ & média $^{(2)}$ \\
\hline \hline $29 / 08$ & 31,6 & 13,1 & 22,1 & 48 & 20 & 48 & 41,0 \\
$30 / 08$ & 31,8 & 14,6 & 21,9 & 52 & 29 & 58 & 49,3 \\
$31 / 08$ & 31,5 & 12,8 & 21,0 & 51 & 16 & 52 & 42,8 \\
$01 / 09$ & 32,1 & 14,0 & 21,4 & 48 & 21 & 57 & 40,8 \\
$02 / 09$ & 33,9 & 11,9 & 22,3 & 53 & 15 & 43 & 38,5 \\
\hline \hline
\end{tabular}

"1) média compensada $=\left\{t^{\circ}(9 h)+2\left[t^{\circ}(21 h)\right]+t^{\circ} \max +t^{\circ} \min \right\} / 5$

(2) média compensada $=\{U R(9 h)+U R(15 h)+2[U R(21 h)]\} / 4$ 
Os dados do grau de umidade das sementes desde o momento da chegada e durante o período de coleta das parcelas encontram-se na Tabela 3. Verifica-se comportamento decrescente no decorrer do período considerado, o que é lógico, uma vez que as espigas contidas nos "bags" (blocos) encontravam-se em sistema aberto de trocas de vapor d'água com o ambiente.

Tabela 3. Grau de umidade das sementes de milho em espiga no momento da chegada à UBS e durante o período de retardamento de secagem. Sete Lagoas - MG, 1995.

\begin{tabular}{ccccc}
\hline \multirow{2}{*}{$\begin{array}{c}\text { Tempo } \\
\text { (h após chegada) }\end{array}$} & \multicolumn{4}{c}{ Teor de água (\%) (1) } \\
\cline { 2 - 5 } & Bloco & Bloco II & Bloco III & Média \\
\hline \hline 0 & 33,6 & 32,4 & 30,4 & 32,1 \\
16 & 29,7 & 31,2 & 29,0 & 30,0 \\
24 & 30,2 & 30,9 & 30,2 & 30,4 \\
32 & 26,6 & 29,6 & 28,2 & 28,1 \\
40 & 29,8 & 27,0 & 27,5 & 28,1 \\
48 & 25,4 & 28,0 & 27,6 & 27,0 \\
56 & 28,8 & 27,2 & 27,6 & 27,9 \\
64 & 28,1 & 26,4 & 26,9 & 27,1 \\
72 & 26,4 & 26,4 & 26,6 & 26,5 \\
80 & 27,0 & 28,0 & 27,8 & 27,6 \\
88 & 27,6 & 27,3 & 27,4 & 27,4 \\
96 & 28,0 & 26,7 & 25,9 & 26,9 \\
104 & 27,6 & 27,6 & 27,6 & 27,6 \\
112 & 26,9 & 25,6 & 27,6 & 26,7 \\
120 & 26,6 & 25,5 & 27,6 & 26,6 \\
\hline
\end{tabular}

(1) Tempo 0: método de estufa a $105^{\circ} \mathrm{C} \pm 3^{\circ} \mathrm{C} / 24 \mathrm{~h}$.

Demais tempos : método indireto (Universal). 
Verifica-se pelos dados da Tabela 3, que a queda do teor de água das sementes foi rápida durante o período considerado, o que se explica pelos baixos valores de umidade relativa do ar ambiente apontados na Tabela 2 .

\subsection{Temperatura da massa de espigas durante o retardamento}

A temperatura da massa de espigas foi tomada através da inserção de sensor térmico no centro de um dos "bags", acoplado a monitor externo, cujos dados, comparados aos do ar ambiente encontram-se na Tabela 4.

Tabela 4. Temperatura da massa de sementes de milho em espiga e do ar ambiente durante o retardamento de secagem. Sete Lagoas - MG, 1995.

\begin{tabular}{ccccc}
\hline Dia & Horário & Retardamento $(\mathrm{h})$ & to $^{\circ}$ da massa $\left({ }^{\circ} \mathrm{C}\right)$ & t$^{\circ}$ ambiente $\left({ }^{\circ} \mathrm{C}\right)$ \\
\hline \hline $29 / 08 / 95$ & $16: 00$ & 16 & 26,2 & 28,0 \\
$30 / 08 / 95$ & $00: 00$ & 24 & 28,0 & 18,0 \\
$30 / 08 / 95$ & $08: 00$ & 32 & 24,9 & 18,0 \\
$30 / 08 / 95$ & $16: 00$ & 40 & 25,7 & 30,0 \\
$31 / 08 / 95$ & $00: 00$ & 48 & 27,0 & 18,0 \\
$31 / 08 / 95$ & $08: 00$ & 56 & 24,2 & 17,0 \\
$31 / 08 / 95$ & $16: 00$ & 64 & 23,6 & 30,0 \\
$01 / 09 / 95$ & $00: 00$ & 72 & 25,1 & 19,0 \\
$01 / 09 / 95$ & $08: 00$ & 80 & 24,5 & 17,0 \\
$01 / 09 / 95$ & $16: 00$ & 88 & 24,4 & 30,0 \\
$02 / 09 / 95$ & $00: 00$ & 96 & 24,5 & 16,0 \\
$02 / 09 / 95$ & $08: 00$ & 104 & 23,2 & 17,0 \\
$02 / 09 / 95$ & $16: 00$ & 112 & 22,0 & 32,0 \\
$03 / 09 / 95$ & $00: 00$ & 120 & 23,2 & 16,0 \\
\hline \hline Média & & & 24,7 & 21,8 \\
\hline \hline
\end{tabular}


Observou-se que a temperatura da massa esteve sempre superior à temperatura ambiente, sob tomadas às $00: 00 \mathrm{~h}$ e 08:00 $\mathrm{h}$, porém nunca ultrapassando $28^{\circ} \mathrm{C}$, temperatura considerada baixa em face do elevado teor de água das sementes. Martinelli (1985), também observou aquecimento não muito elevado, seguido inclusive de posterior resfriamento, em sementes de sorgo submetidas a retardamento de secagem com $18 \%$ a $20,4 \%$ de grau de umidade.

Segundo Muir (1973), o aquecimento de grãos é dissipado mais rapidamente em recipientes pequenos do que em grandes, em função da pequena distância do centro até a parede, consequentemente com menores niveis de deterioração das sementes. Outra explicação que parece lógica é a de que, em face do baixo peso específico do milho em espigas, devido à baixa acomodação das espigas umas sobre as outras, gerando espaços entre elas, o calor gerado é facilmente dissipado por convecção para o meio externo, uma vez que as espigas encontravam-se armazenadas em sistema aberto.

Assim a ausência de elevação da temperatura da massa, ao contrário, com decréscimo durante o período considerado, passou a ser um indicativo que justificaria maior tolerância das sementes ao retardamento de secagem, o que será comentado mais adiante. 


\subsection{Evolução da secagem}

Visando o conhecimento do comportamento do teor de água das sementes durante a secagem, foram tomadas amostras a partir de parcela adicional submetida a secagem juntamente com aquela referente ao $1^{\circ}$ tempo de retardamento ( 16 horas), determinando-se o grau de umidade das sementes a cada 24 horas, encerrando-se o estudo quando estas se apresentaram abaixo de $13 \%$, conforme Tabela 5 .

Tabela 5. Comportamento do teor de água das sementes de milho em espiga durante o período de secagem. Sete Lagoas - MG, 1995.

\begin{tabular}{l|ccccccc|cc}
\hline \hline Bloco & \multicolumn{7}{|c|}{ Teor de água às 16:00 horas } & \multicolumn{2}{c}{ Secagem } \\
\cline { 2 - 11 } & $29 / 8$ & $30 / 8$ & $31 / 8$ & $01 / 9$ & $02 / 9$ & $03 / 9$ & $04 / 9^{(1)}$ & tempo (h) & taxa (\%/h) \\
\hline \hline I & 30,4 & 25,6 & 21,4 & 17,7 & 15,6 & 13,5 & 12,4 & 136 & 0,1323 \\
II & 29,2 & 24,5 & 20,8 & 16,0 & 14,6 & 13,8 & 12,8 & 136 & 0,1205 \\
III & 30,6 & 24,4 & 21,5 & 17,7 & 14,5 & 13,4 & 12,7 & 136 & 0,1316 \\
\hline \hline Média & 30,1 & 24,8 & 21,2 & 17,1 & 14,9 & 13,6 & 12,6 & 136 & 0,1287 \\
\hline (1) determinação às $8: 00 \mathrm{~h}$
\end{tabular}

Quanto ao estudo da secagem das sementes de cada tratamento, este não foi executado, em vista da necessidade de disponibilidade de maior número de espigas, 0 que poderia comprometer 0 volume necessário às diversas avaliações subsequentes, ou ainda o volume remanescente presente em cada bloco, aumentando a porcentagem de utilização de espigas, calculada 
em 16,3\%. De acordo com Nogueira' este percentual não deve exceder a $20 \%$, limite arbitrado por bom senso, para que o ambiente experimental não seja alterado.

Assim o comportamento da secagem de cada tratamento se deu através da coleta de amostras a partir do terceiro dia de secagem, secagem esta encerrada quando as sementes apresentaram-se com grau de umidade inferior a $14 \%$, obtido através do determinador Universal. Repetidas as determinações pelo método da estufa a $105^{\circ} \mathrm{C} \pm 3^{\circ} \mathrm{C}$, os resultados indicaram valores ao redor de 2 pontos percentuais abaixo, conforme dados apresentados na Tabela 6.

Também na mesma tabela, estão apresentados os períodos de secagem aos quais cada tratamento esteve sujeito, bem como as respectivas taxas de secagem, considerando o teor final de água obtido pelo método da estufa a $105^{\circ} \mathrm{C} \pm 3^{\circ} \mathrm{C}$. A variação de $2,6 \%$ entre o máximo teor de água final $(12,7 \%$, tratamento $104 \mathrm{~h})$ e o mínimo $(10,1 \%$, tratamentos $16 \mathrm{~h}$ e $24 \mathrm{~h})$ é justificada pela dificuldade de obtenção de amostras representativas diante de universo reduzido de apenas 30 espigas em cada tratamento.

Embora consideráveis, tais variações não influenciaram os resultados subsequentes, uma vez que utilizou-se de processo de debulha não promotor de danificações mecânicas e pelo fato de as sementes terem passado por periodo de uniformização do teor de água em câmara fria e seca.

\footnotetext{
${ }^{1}$ NOGUEIRA, M. C. S. (ESALQ - Departamento de Matemática e Estatística, Piracicaba - SP) Comunicação pessoal. 1995.
} 
As variações no período e taxa de secagem são explicadas devido ao fato de que, à medida que as parcelas eram levadas ao secador, foram sendo preenchidos os espaços livres sobre seu fundo, aumentando consequentemente a pressão estática do ar insuflado. Outro fato que concorreu para tal variação, são os dados decrescentes da umidade relativa média do ar no período, apresentados na Tabela 2.

Tabela 6. Grau inicial e final de umidade, período e taxa de secagem das sementes de milho em espigas. Sete Lagoas - MG, 1995.

\begin{tabular}{|c|c|c|c|c|c|}
\hline \multirow[t]{2}{*}{ Tratamento } & \multicolumn{3}{|c|}{ Teor de água (\%) } & \multirow{2}{*}{$\begin{array}{c}\text { Tempo de } \\
\text { secagem (h) }\end{array}$} & \multirow{2}{*}{$\begin{array}{l}\text { Taxa de seca } \\
\text { gem }(\% / h)\end{array}$} \\
\hline & inicial (1) & final (1) & final (2) & & \\
\hline 16 & 30,0 & 11,8 & $\overline{10,1}$ & 143 & 0,139 \\
\hline 24 & 30,4 & 11,4 & 10,1 & 154 & 0,132 \\
\hline 32 & 28,1 & 12,5 & 10,8 & 146 & 0,118 \\
\hline 40 & 28,1 & 13,3 & 11,7 & 139 & 0,118 \\
\hline 48 & 27,0 & 13,1 & 11,3 & 131 & 0,120 \\
\hline 56 & 27,9 & 13,5 & 11,6 & 123 & 0,132 \\
\hline 64 & 27,1 & 12,6 & 10,5 & 120 & 0,138 \\
\hline 72 & 26,5 & 13,1 & 11,2 & 112 & 0,137 \\
\hline 80 & 27,6 & 12,9 & 10,8 & 105 & 0,131 \\
\hline 88 & 27,4 & 14,3 & 12,0 & 117 & 0,132 \\
\hline 96 & 26,9 & 12,6 & 10,9 & 107 & 0,149 \\
\hline 104 & 27,6 & 14,6 & 12,7 & 99 & 0,150 \\
\hline 112 & 26,7 & 14,6 & 12,5 & 96 & 0,148 \\
\hline 120 & 26,6 & 13,5 & 12,0 & 90 & 0,162 \\
\hline
\end{tabular}

Obs: (1): resultados médios obtidos pelo determinador Universal, de amostra tomada da parcela em espigas (para determinação de término da secagem).

(2) : resultados médios obtidos pelo método de estufa a $105^{\circ} \mathrm{C} \pm 3^{\circ} \mathrm{C}$, de amostra tomada da parcela debulhada (para confirmação pelo método direto). 
Mesmo considerando que os valores mais baixos do teor de água poderiam ser indicadores de secagem excessiva, tal fato segundo Herter \& Burris (1989), não promove efeitos negativos sobre a qualidade das sementes de milho em espiga, se utilizadas temperaturas inferiores a $40^{\circ} \mathrm{C}$ (no presente estudo, a temperatura adotada nunca foi superior a $35^{\circ} \mathrm{C}$ ).

\subsection{Avaliação de sanidade das sementes}

Os testes de sanidade efetuados a partir de sementes não tratadas de cada tratamento, realizados com o objetivo de se verificar 0 comportamento da população de microrganismos patogênicos durante 0 período de retardamento de secagem, revelaram, de acordo com resultados mencionados na Tabela 7 , alta incidência dos fungos Fusarium moniliforme e Penicillium spp., indistintamente em todos os tratamentos, o que está de acordo com Cicero et al., 1991, que afirmam ser, em sementes de milho, os de maior ocorrência e frequência, respectivamente.

Quanto a Aspergillus spp., em menor intensidade devido possivelmente à menor infestação no campo e ao pequeno período considerado, observou-se, à semelhança dos demais, exceto Cephalosporium spp. e Cladosporium sp, a tendência decrescente de ocorrência, à medida que se aumentou o tempo de retardamento de secagem, o que segundo Pinto ${ }^{2}$

\footnotetext{
${ }^{2}$ PINTO, N. F. J. A. (EMBRAPA - CNPMS, Sete Lagoas - MG) Comunicação pessoal. 1996.
} 
poderia estar relacionado à presença dominante de Fusarium moniliforme e Penicillium spp.

Cephalosporium spp. e Cladosporium sp, foram observados em intensidade media e variável entre tratamentos, sendo o primeiro, juntamente com Fusarium moniliforme, considerados por Pinto (1991) como um dos principais fungos que infestam as sementes de milho no campo.

Durante o período de retardamento de secagem considerado, não foram portanto verificados aumentos na população destes microrganismos, não constituindo fator que pudesse justificar perdas na qualidade fisiológica das sementes.

Com relação à presença destes patógenos nas sementes durante o periodo de armazenamento, notadamente fusarium moniliforme, Cephalosporium spp., Aspergillus spp. e Penicillium spp., Pinto (1991) afirmou não afetarem a qualidade fisiológica das sementes sob condições adequadas de armazenamento, como as aqui observadas.

Contudo visando maior segurança e em função de resultados favoráveis obtidos por Koch et al. (1995), Moraes et al. (1995), citações de Pinto (1991) e Pereira (1986), além do uso generalizado entre as empresas produtoras de sementes de milho, procedeu-se ao tratamento químico com o uso do fungicida Captan, em dosagem citada em "Materiais e Métodos. 
Tabela 7. Resultados dos testes de sanidade em sementes de milho não tratadas, submetidas ao retardamento de secagem em espigas: dados médios (\%) de ocorrência por patógeno. Sete Lagoas, 1995.

\begin{tabular}{ccccccccccccc}
\hline \hline Trat & Fus & Pen & Asp & Cep & Cla & Alt & Rhi & Pho & Dre & Cur & Epi & Nig \\
\hline \hline 16 & 92,3 & 98,0 & 4,0 & 12,0 & 26,8 & 0,5 & 3,5 & 0,3 & 0,3 & 0,7 & 8,0 & 0,8 \\
24 & 92,0 & 98,2 & 6,3 & 13,0 & 16,8 & 1,7 & 2,5 & 0,2 & 0,2 & 0,8 & 5,5 & 0,3 \\
32 & 86,0 & 97,3 & 2,2 & 6,8 & 16,5 & 0,8 & 2,0 & 0,0 & 0,3 & 0,5 & 2,3 & 0,3 \\
40 & 93,0 & 98,8 & 2,2 & 9,5 & 14,5 & 0,7 & 0,5 & 0,3 & 0,3 & 0,3 & 3,5 & 0,5 \\
48 & 92,8 & 88,5 & 2,2 & 21,8 & 23,0 & 1,3 & 2,0 & 0,2 & 0,5 & 0,5 & 3,5 & 0,3 \\
56 & 96,8 & 95,0 & 0,5 & 27,7 & 23,5 & 0,3 & 0,7 & 0,3 & 1,0 & 0,0 & 1,7 & 0,7 \\
64 & 80,2 & 98,8 & 0,2 & 14,0 & 15,2 & 0,7 & 1,8 & 0,2 & 0,3 & 0,0 & 0,7 & 0,2 \\
72 & 90,3 & 99,0 & 0,2 & 9,3 & 7,7 & 0,3 & 1,2 & 0,8 & 0,3 & 0,0 & 1,2 & 0,0 \\
80 & 94,7 & 97,7 & 1,3 & 11,0 & 24,8 & 0,7 & 1,5 & 0,0 & 0,3 & 0,5 & 1,3 & 0,0 \\
88 & 89,7 & 99,2 & 0,2 & 11,3 & 18,2 & 1,3 & 3,7 & 0,0 & 0,3 & 0,3 & 2,0 & 0,0 \\
96 & 89,7 & 98,8 & 0,7 & 8,0 & 15,5 & 1,8 & 2,0 & 0,3 & 0,2 & 0,0 & 0,7 & 0,2 \\
104 & 83,8 & 97,7 & 0,5 & 15,2 & 12,2 & 0,2 & 0,5 & 0,2 & 0,3 & 0,0 & 1,0 & 0,0 \\
112 & 91,0 & 95,8 & 0,5 & 21,0 & 25,0 & 0,3 & 0,8 & 0,0 & 0,2 & 0,0 & 0,0 & 0,2 \\
120 & 96,7 & 99,5 & 0,5 & 16,8 & 14,8 & 0,3 & 0,7 & 0,5 & 0,0 & 0,0 & 0,2 & 0,2 \\
\hline \hline
\end{tabular}

\begin{tabular}{|c|c|c|c|c|}
\hline \multirow[t]{6}{*}{ Legenda: } & Fus. & Fusarium moniliforme & Rhi. & Rhizopus sp \\
\hline & Pen. & Penicillium spp. & Pho & Phoma sp \\
\hline & Asp. & Aspergillus spp. & Dre . & Drechslera sp \\
\hline & Cep ........... & Cephalosporium spp. & Cur. & Curvularia sp \\
\hline & $\mathrm{Cla} . . . . . . . . .$. & Cladosporium sp & Epi ............. & Epicocum sp \\
\hline & Alt .............. & Alternaria sp & Nig ............ & Nigrospora spp. \\
\hline
\end{tabular}




\subsection{Efeitos do retardamento durante o armazenamento}

As variações no teor de água das sementes no início do armazenamento ( $2,6 \%$ na média dos 3 blocos), minimizadas pelo período de exposição em câmara fria e seca, não influenciaram os resultados dos testes para avaliação da qualidade fisiológica das sementes. Tais variações, reduziram-se drasticamente durante o período de armazenamento, em função do equilibrio higroscópico com o ar ambiente, e podem ser observadas na Tabela 8.

Tabela 8. Teor de água das sementes de milho submetidas a diferentes periodos de retardamento de secagem ainda em espigas, no inicio, aos 6 meses e aos 12 meses de armazenamento. Sete Lagoas-MG, 1995/96.

\begin{tabular}{cccc}
\hline \hline Tratamento & \multicolumn{3}{c}{ Armazenamento } \\
\cline { 2 - 4 } & 0 mes & 6 meses & 12 meses \\
\hline \hline 16 & 10,1 & 11,2 & 10,6 \\
24 & 10,1 & 11,5 & 10,7 \\
32 & 10,8 & 11,4 & 10,7 \\
40 & 11,7 & 11,6 & 10,5 \\
48 & 11,3 & 11,3 & 10,7 \\
56 & 11,6 & 11,3 & 10,8 \\
64 & 10,5 & 11,2 & 10,7 \\
72 & 11,2 & 11,5 & 10,4 \\
80 & 10,8 & 11,8 & 10,6 \\
88 & 12,0 & 11,5 & 10,9 \\
96 & 10,9 & 11,1 & 10,7 \\
104 & 12,7 & 11,7 & 10,6 \\
112 & 12,5 & 11,5 & 10,7 \\
120 & 12,0 & 11,5 & 10,8 \\
\hline \hline
\end{tabular}


Durante este período foram registradas as condições do ar ambiente, conforme dados da Tabela 9.

Tabela 9. Médias mensais de temperatura $\left({ }^{\circ} \mathrm{C}\right)$ e de umidade relativa (\%) em Sete Lagoas-MG, no período de agosto $/ 95$ a julho/96.

\begin{tabular}{lccccccc}
\hline \hline \multirow{2}{*}{ Mes } & \multicolumn{3}{c}{${\text { Temperatura }\left({ }^{\circ} \mathrm{C}\right)}$} & \multicolumn{3}{c}{ Umidade Relativa (\%) } \\
\cline { 2 - 8 } & max. & min. & média $^{(1)}$ & $9 \mathrm{~h}$ & $15 \mathrm{~h}$ & $21 \mathrm{~h}$ & média $^{(2)}$ \\
\hline \hline Agosto & 29,9 & 13,7 & 20,8 & 58 & 28 & 59 & 51 \\
Setembro & 29,8 & 15,2 & 21,6 & 58 & 35 & 62 & 54 \\
Outubro & 30,6 & 17,7 & 23,0 & 66 & 42 & 72 & 63 \\
Novembro & 28,3 & 17,3 & 21,9 & 70 & 56 & 79 & 71 \\
Dezembro & 29,0 & 18,8 & 22,8 & 79 & 65 & 87 & 80 \\
Janeiro & 30,9 & 18,3 & 23,7 & 71 & 53 & 79 & 71 \\
Fevereiro & 31,1 & 18,9 & 23,7 & 72 & 53 & 84 & 73 \\
Março & 30,7 & 18,8 & 23,6 & 73 & 55 & 86 & 75 \\
Abril & 29,0 & 16,5 & 21,5 & 70 & 50 & 81 & 71 \\
Maio & 26,9 & 13,1 & 18,6 & 74 & 46 & 83 & 72 \\
Junho & 26,3 & 11,0 & 17,1 & 71 & 39 & 78 & 67 \\
Julho & 27,1 & 11,0 & 17,6 & 68 & 35 & 70 & 61 \\
\hline \hline
\end{tabular}

(1) média compensada $=\left\{t^{\circ}(9 h)+2\left[t^{\circ}(21 h)\right]+t^{\circ} \max +t^{\circ} \min \right\} / 5$

(2) média compensada $=\{U R(9 h)+U R(15 h)+2[U R(21 h)]\} / 4$

Os resultados do desempenho fisiológico das sementes, obtidos no inicio, aos 6 meses e aos 12 meses de armazenamento encontram-se nas tabelas 10,11 e 12 respectivamente, já com a aplicação do teste " $F$ ", através da análise de regressão polinomial. 
Tabela 10. Testes de germinação - TG (\%), de envelhecimento acelerado - EA (\%), de frio - TF (\%), de emergência em campo - EC (\%), índice de velocidade de emergência - IVE e teste de condutividade elétrica -CE ( $\mu \mathrm{mhos} / \mathrm{cm} / \mathrm{g})$ : dados médios considerando o tempo de retardamento de secagem a que foram submetidas sementes de milho em espigas, no início do armazenamento. Sete Lagoas - MG, 1995.

\begin{tabular}{rcccccc}
\hline \hline Tempo & \multicolumn{5}{c}{ Primeira época (0 mes de armazenamento) } \\
\cline { 2 - 7 } (horas) & TG & EA & TF & EC & IVE & CE \\
& $(\%)$ & $(\%)$ & $(\%)$ & $(\%)$ & & $(\mu \mathrm{mhos} / \mathrm{cm} / \mathrm{g})$ \\
\hline 16 & 97,00 & 96,33 & 93,00 & 99,00 & 10,03 & 12,65 \\
24 & 97,67 & 97,33 & 95,67 & 98,00 & 9,75 & 11,86 \\
32 & 97,67 & 96,67 & 96,00 & 97,33 & 9,62 & 12,57 \\
40 & 96,67 & 94,67 & 92,00 & 96,67 & 9,99 & 12,18 \\
48 & 98,33 & 96,67 & 97,67 & 99,00 & 9,64 & 11,52 \\
56 & 97,00 & 96,00 & 95,00 & 95,67 & 9,53 & 10,92 \\
64 & 97,67 & 97,33 & 95,33 & 98,33 & 9,78 & 11,37 \\
72 & 98,67 & 95,00 & 95,00 & 99,00 & 9,87 & 11,98 \\
80 & 96,67 & 96,33 & 96,00 & 99,67 & 9,78 & 11,11 \\
88 & 97,67 & 96,00 & 95,33 & 98,00 & 9,95 & 11,92 \\
96 & 97,00 & 95,67 & 96,67 & 98,67 & 9,73 & 10,70 \\
104 & 97,00 & 95,33 & 93,33 & 98,33 & 9,95 & 10,43 \\
112 & 97,67 & 95,33 & 94,33 & 99,00 & 9,80 & 11,29 \\
120 & 97,00 & 95,67 & 98,67 & 97,33 & 9,73 & 11,19 \\
\hline \hline
\end{tabular}

NS - ausência de significância

(*) - significância ao nível de $5 \%$ de probabilidade

(**) - significância ao nivel de $1 \%$ de probabilidade 
Tabela 11. Testes de germinação - TG (\%), de envelhecimento acelerado - EA (\%), de frio - TF (\%), de emergência em campo - EC (\%), índice de velocidade de emergência - IVE e teste de condutividade elétrica -CE $(\mu \mathrm{mhos} / \mathrm{cm} / \mathrm{g})$ : dados médios considerando o tempo de retardamento de secagem a que foram submetidas sementes de milho em espigas, aos 6 meses de armazenamento. Sete Lagoas - MG, 1995.

\begin{tabular}{|c|c|c|c|c|c|c|}
\hline \multirow{3}{*}{$\begin{array}{l}\text { Tempo } \\
\text { (horas) }\end{array}$} & \multicolumn{6}{|c|}{ Segunda época (6 meses de armazenamento) } \\
\hline & \multirow{2}{*}{$\begin{array}{l}\text { TG } \\
(\%)\end{array}$} & \multirow{2}{*}{$\begin{array}{l}\text { EA } \\
(\%)\end{array}$} & \multirow{2}{*}{$\begin{array}{l}\text { TF } \\
(\%)\end{array}$} & \multirow{2}{*}{$\begin{array}{l}E C \\
(\%)\end{array}$} & \multirow[t]{2}{*}{ IVE } & \multirow{2}{*}{$\begin{array}{c}\text { CE } \\
(\mu \mathrm{mhos} / \mathrm{cm} / \mathrm{g})\end{array}$} \\
\hline & & & & & & \\
\hline 16 & 95,00 & 93,33 & 97,00 & 99,00 & 11,43 & $\overline{14,41}$ \\
\hline 24 & 95,00 & 94,33 & 98,67 & 98,00 & 11,12 & 13,71 \\
\hline 32 & 95,67 & 93,67 & 97,33 & 98,33 & 11,29 & 14,24 \\
\hline 40 & 93,33 & 91,67 & 98,00 & 98,67 & 11,36 & 12,33 \\
\hline 48 & 95,67 & 94,00 & 97,33 & 97,33 & 11,04 & 12,87 \\
\hline 56 & 96,33 & 93,67 & 98,33 & 98,33 & 11,01 & 13,46 \\
\hline 64 & 96,00 & 94,67 & 98,33 & 99,33 & 11,47 & 12,48 \\
\hline 72 & 95,33 & 93,67 & 98,00 & 99,67 & 11,39 & 12,52 \\
\hline 80 & 94,67 & 96,33 & 94,50 & 98,17 & 10,77 & 12,70 \\
\hline 88 & 96,17 & 93,50 & 95,33 & 99,50 & 10,90 & 13,21 \\
\hline 96 & 94,00 & 94,33 & 98,00 & 99,00 & 11,17 & 11,67 \\
\hline 104 & 96,00 & 92,67 & 97,00 & 99,00 & 10,91 & 12,37 \\
\hline 112 & 97,33 & 92,33 & 96,67 & 99,00 & 11,28 & 12,50 \\
\hline 120 & 93,67 & 94,00 & 94,33 & 98,67 & 11,34 & 14,56 \\
\hline Média & 95,30 & 93,73 & 97,06 & 98,71 & 111,18 & 13,07 \\
\hline F linear & NS & NS & NS & NS & NS & * \\
\hline F quadr. & NS & NS & NS & NS & NS & ** \\
\hline CV (\%) & 1,737 & 1,759 & 1,687 & 1,504 & 3,230 & 8,858 \\
\hline $\mathrm{R}^{2}$ & & & & & & 0,468 \\
\hline NS $-a$ & sin & & & & & \\
\hline $\begin{array}{ll}(*) & - \text { sig } \\
(\star \star & - \text { sig }\end{array}$ & & $1 \% d$ & $\begin{array}{l}\text { abilidade } \\
\text { abilidade }\end{array}$ & & & \\
\hline
\end{tabular}


Tabela 12. Testes de germinação - TG (\%), de envelhecimento acelerado - EA (\%), de frio - TF (\%), de emergência em campo - EC (\%), indice de velocidade de emergência - IVE e teste de condutividade elétrica -CE $(\mu \mathrm{mhos} / \mathrm{cm} / \mathrm{g})$ : dados médios considerando o tempo de retardamento de secagem a que foram submetidas sementes de milho em espigas, aos 12 meses de armazenamento. Sete Lagoas - MG, 1995.

\begin{tabular}{ccccccc}
\hline \hline Tempo & \multicolumn{5}{c}{ Terceira época (12 meses de armazenamento) } \\
\cline { 2 - 7 } (horas) & TG & EA & TF & EC & IVE & CE \\
& $(\%)$ & $(\%)$ & $(\%)$ & $(\%)$ & & $(\mu \mathrm{mhos} / \mathrm{cm} / \mathrm{g})$ \\
\hline 16 & 90,67 & 77,33 & 75,67 & 97,67 & 10,39 & 19,83 \\
24 & 91,33 & 83,00 & 81,67 & 96,00 & 10,18 & 18,82 \\
32 & 93,33 & 87,33 & 82,00 & 97,67 & 10,28 & 18,48 \\
40 & 93,33 & 85,91 & 92,00 & 97,00 & 10,39 & 17,34 \\
48 & 93,67 & 79,67 & 87,00 & 96,67 & 10,04 & 16,98 \\
56 & 93,33 & 69,08 & 91,00 & 96,33 & 9,96 & 16,95 \\
64 & 94,67 & 75,00 & 88,00 & 97,33 & 10,14 & 17,45 \\
72 & 94,33 & 74,33 & 92,33 & 97,67 & 10,50 & 17,30 \\
80 & 93,17 & 80,33 & 83,00 & 96,67 & 11,03 & 17,10 \\
88 & 93,17 & 73,00 & 83,33 & 96,00 & 9,42 & 15,84 \\
96 & 94,67 & 79,67 & 92,33 & 95,67 & 10,27 & 15,01 \\
104 & 93,67 & 80,00 & 83,33 & 97,00 & 10,66 & 16,28 \\
112 & 89,33 & 78,00 & 86,00 & 95,67 & 9,81 & 19,49 \\
120 & 90,67 & 66,67 & 85,33 & 93,33 & 9,86 & 21,31 \\
\hline \hline
\end{tabular}


Não foram detectados efeitos provenientes do retardamento de secagem no início e aos 6 meses de armazenamento, à exceção dos resultados fornecidos pelo teste de condutividade elétrica, que indicaram efeitos significativos, linear na primeira época (Figura 1) e quadrático na segunda época (Figura 2).

Quanto à primeira época, o efeito verificado através da análise de regressão linear, apesar de altamente significativo, não foi confirmado por nenhum dos outros testes aplicados e devem-se provavelmente a fatores não controlados durante a realização do experimento e foi considerado contraditório do ponto de vista fisiológico, uma vez que esperavam-se valores mais altos para os períodos mais avançados, em função da previsão quanto ao estágio mais avançado de deterioração destas sementes.

Um dos fatores não controlados pode ter sido o período insuficiente a que as sementes estiveram submetidas em câmara fria e seca para uniformização do teor de água, tendo em vista a importância de seu conhecimento em função de afirmações de Abdul-Baki (1980), que refere-se à ineficiência das organelas de sementes secas, entre $12 \%$ e $14 \%$, como barreiras à perda de solutos, e de Tao (1978) de que, em sementes de soja, acréscimos nos valores de condutividade elétrica estão relacionados, entre outros fatores, a teores baixos de água ( $8,8 \%$ ou menores). 
Quanto a segunda época, a tendência verificada pela curva da Figura 2, obtida através de análise de regressão quadrática, também não confirmada por nenhum dos outros testes utilizados, se lógica a partir do ponto de inflexão da curva, em torno de 72 horas, é ineperada antes deste. Tal tendência, obtida pela equação mencionada na Figura 2, apesar de calcada em parâmetros altamente significativos, representa pouco 0 fenômeno $\left(R^{2}=\right.$ $0,468)$.

Assim com base nestas considerações e ainda análise de Fratin (1987) que constatou variações nos resultados fornecidos pelo teste de condutividade elétrica em função do cultivar, promovendo inclusive inversões na avaliação da qualidade de lotes de sementes de milho em relação aos demais testes aplicados (germinação, emergência de plântulas em campo, primeira contagem no teste de germinação e testes de frio, com e sem a utilização de solo), até esta época foram julgados irrelevantes os resultados obtidos através deste teste, pelo menos nos 2 primeiros periodos de armazenamento.

Contudo se considerado que o teste baseia-se na integridade do sistema de membranas celulares (Woodstock, 1973; Grabe, 1976), que o grau de organização deste sistema é máximo na maturidade fisiológica da semente (Abdul-Baki, 1980) e que os primeiros sintomas de deterioração, muito antes de serem detectados por outros testes de viabilidade, referem-se à perda de integridade das membranas celulares (Roberts, 1986), podemos estar diante 
dos possíveis primeiros efeitos latentes do retardamento de secagem. Porém como explicar a tendência decrescente da curva até seu ponto de inflexão?

Algumas hipóteses podem ser formuladas, sendo a primeira, a que parece mais lógica, o fato de que, apesar de colhidas aos 79 dias após o início do florescimento, nem todas as sementes tivessem atingido o ponto de maturidade fisiológica, notadamente as localizadas no ápice da espiga. Sob condições climáticas semelhantes, a maturidade fisiológica deste material ocorre aos 58 dias após o início do florescimento (Borba et al., 1995a).

Assim as sementes poderiam ter concluido a fase final do processo de maturação ainda na espiga, durante parte do processo de retardamento de secagem. Isto explicaria o período de até 72 horas onde houve redução significativa nos valores da condutividade elétrica apontados pelo teste, período este promotor de qualidade, até que diante das condições adversas pelo alto grau de umidade das sementes, fatores de deterioração fossem dominantes.

Outra hipótese diz respeito a mecanismos de reparação e/ou organização de membranas que estariam ocorrendo neste período de até 72 horas de retardamento onde, submetidas a teores de água elevados, as sementes estariam sofrendo um processo de condicionamento fisiológico.

Já com relação ao desempenho fisiológico das sementes aos 12 meses de armazenamento (Tabela 12), todos os testes aplicados revelaram efeitos provenientes do retardamento de secagem, com exceção do teste de 
velocidade de emergência, cujas variações no índice obtido (IVE) não foram significativas, devido possivelmente ao baixo estresse a que as sementes estiveram submetidas.

A análise de regressão dos resultados dos testes de envelhecimento acelerado e de emergência em campo revelou efeito linear decrescente (Figuras 3 e 4 respectivamente). 


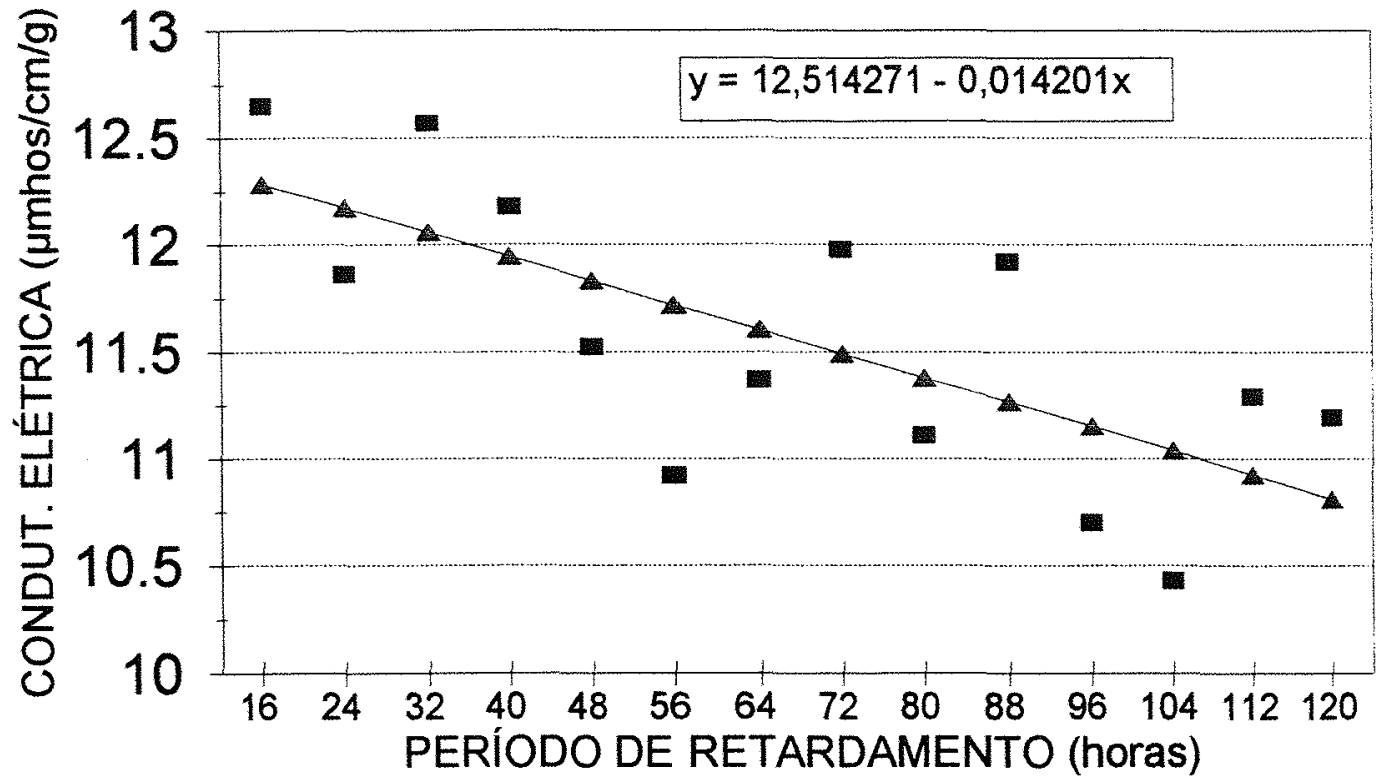

- PONTOS ESTIMADOS PELAEQUAÇÃO = PONTOS OBSERVADOS

Figura 1. Gráfico dos resultados do teste de condutividade elétrica na primeira época ( 0 mes): dados médios observados e estimados pela equação de regressão linear.

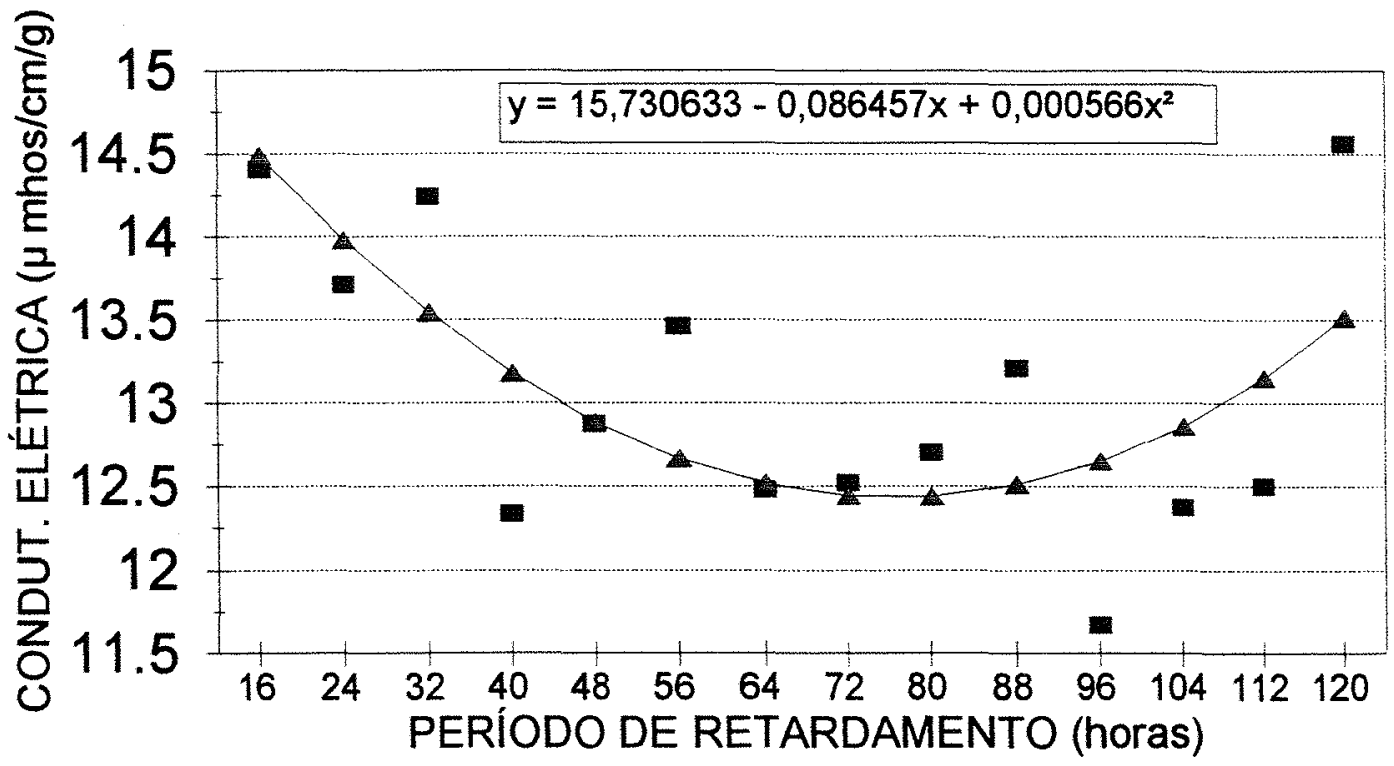

PONTOS OBSERVADOS

- PONTOS ESTIMADOS PELA EQUAÇÃO

Figura 2. Gráfico dos resultados do teste de condutividade elétrica na segunda época (6 meses): dados médios observados e estimados pela equação de regressão quadrática. 


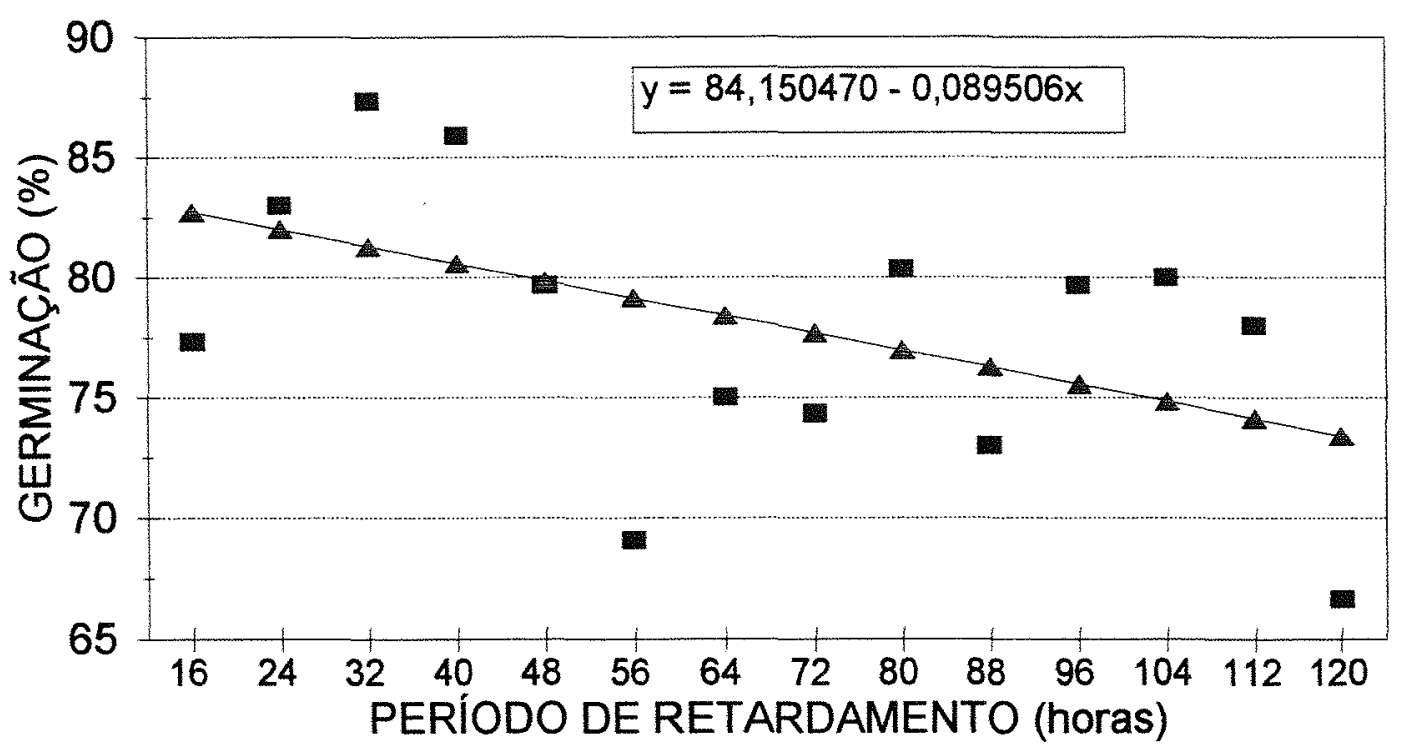

- PONTOS OBSERVADOS

PONTOS ESTIMADOS PELA EQUAÇÃO

Figura 3. Gráfico dos resultados do teste de envelhecimento acelerado na terceira época (12 meses): dados médios observados e estimados pela equação de regressão linear.

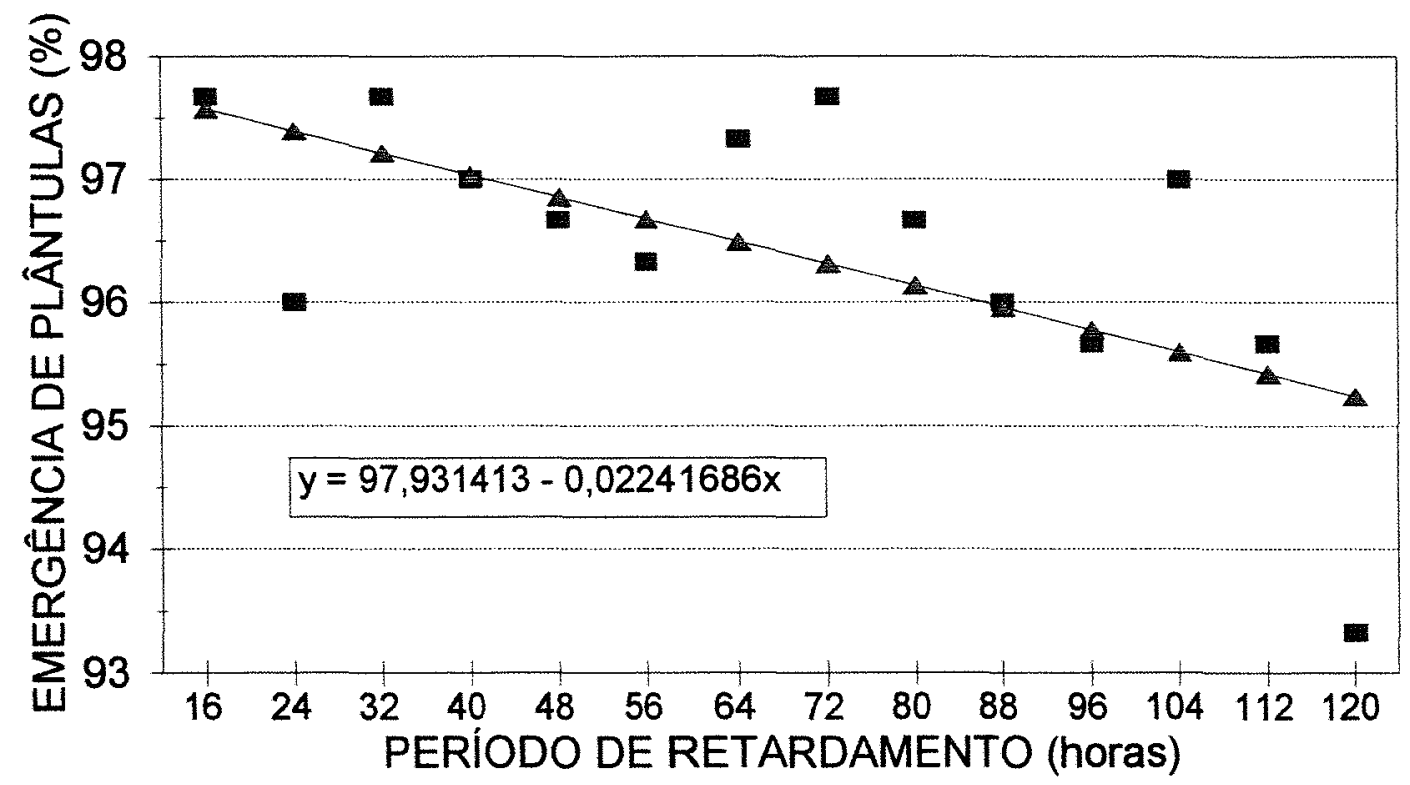

- PONTOS OBSERVADOS — PONTOS ESTIMADOS PELA EQUAÇÃO

Figura 4. Gráfico dos resultados do teste de emergência em campo na terceira época (12 meses): dados médios observados e estimados pela equação de regressão linear. 
Quanto a análise do teste de envelhecimento acelerado, apesar de haver efeitos significativos, a equação pouco explica o fenômeno, uma vez que apenas $24,7 \%\left(R^{2}=0,247\right)$ dos pontos observados coincidem com a reta, não apresentando portanto resultados conclusivos.

Já a análise dos resultados de teste de emergência em campo permite observar, muito embora o teste " $F$ " na análise de regressão linear revele efeitos significativos e o modelo apresente coeficiente de determinação pouco superior ao caso anterior $\left(R^{2}=0,425\right)$, elevados valores reais (máximo de $97,67 \%$ e mínimo de $93,33 \%$ ) e estimados (máximo de $97,57 \%$ e mínimo de $95,24 \%$ ), não permitindo inferir-se quanto à possíveis quedas na qualidade fisiológica.

Quanto às análises estatísticas dos resultados dos demais testes aplicados na terceira época, ("germinação", "frio" e "condutividade elétrica"), estas revelaram valores altamente significativos através da aplicação do teste "F", cujos efeitos, revelados pelas equações de regressão quadrática, encontram-se representados pelas curvas constantes das Figuras 5,6 e 7 , respectivamente. 


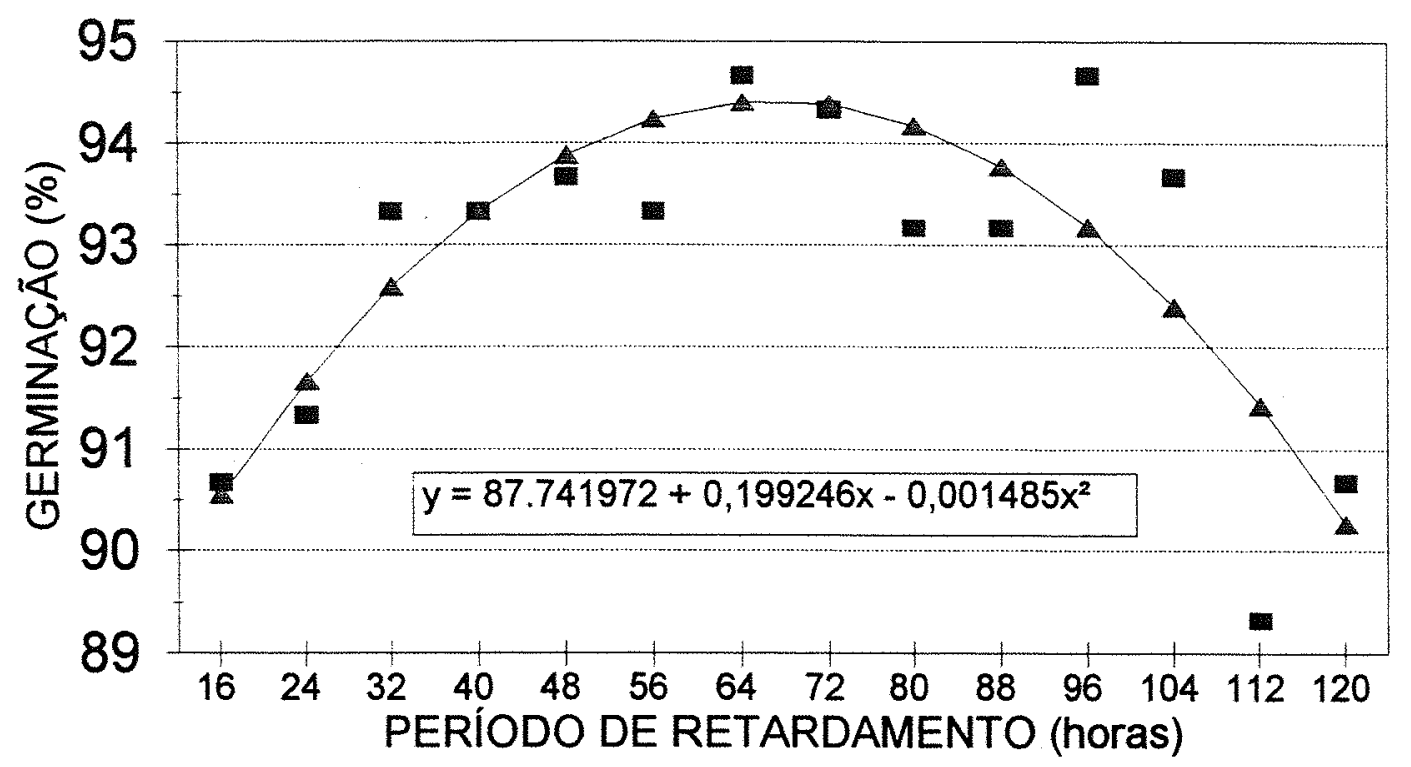

- PONTOS OBSERVADOS PONTOS ESTIMADOS PELA EQUAÇÃO

Figura 5. Gráfico dos resultados do teste de germinação na terceira época (12 meses): dados médios observados e estimados pela equação de regressão quadrática.

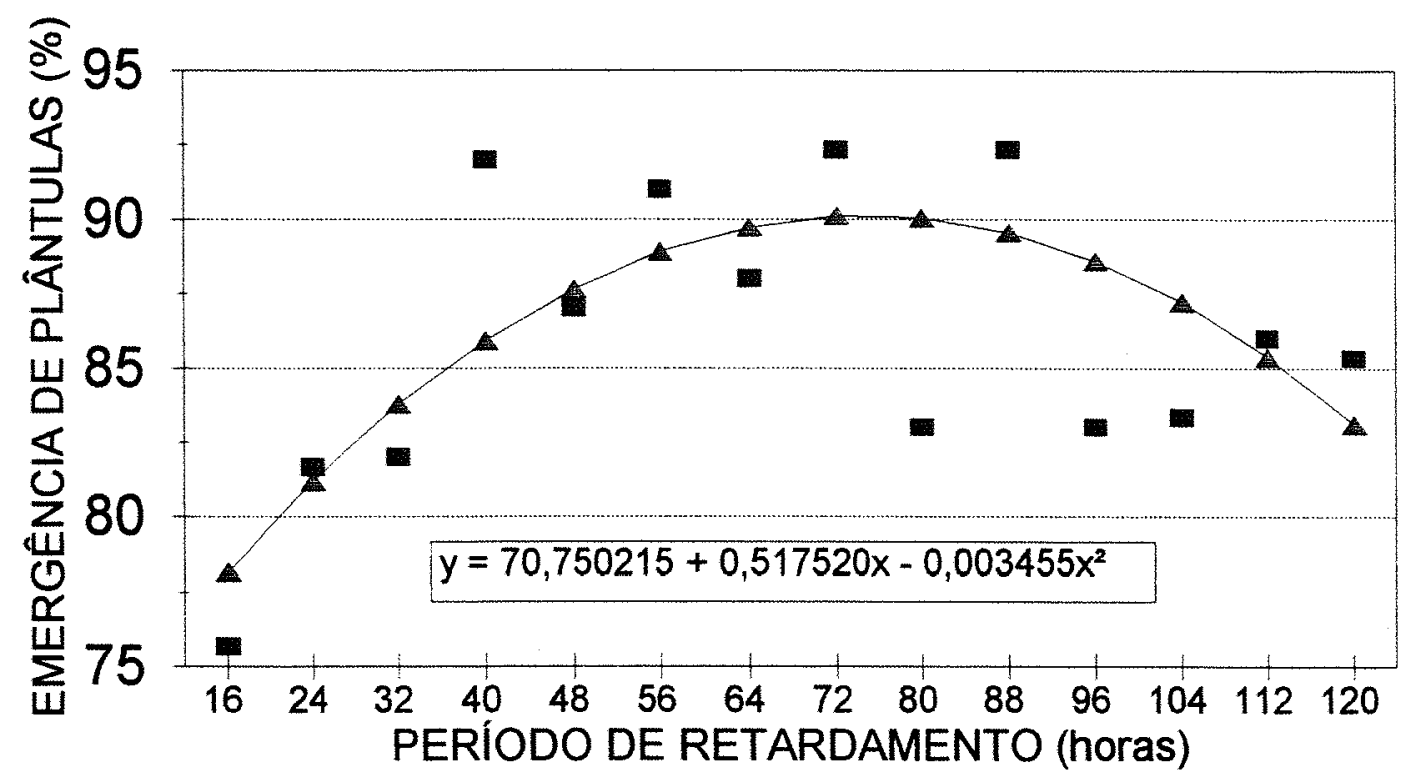

- PONTOS OBSERVADOS PONTOS ESTIMADOS PELAEQUAÇÃO

Figura 6. Gráfico dos resultados do teste de frio na terceira época (12 meses): dados médios observados e estimados pela equação de regressão quadrática. 


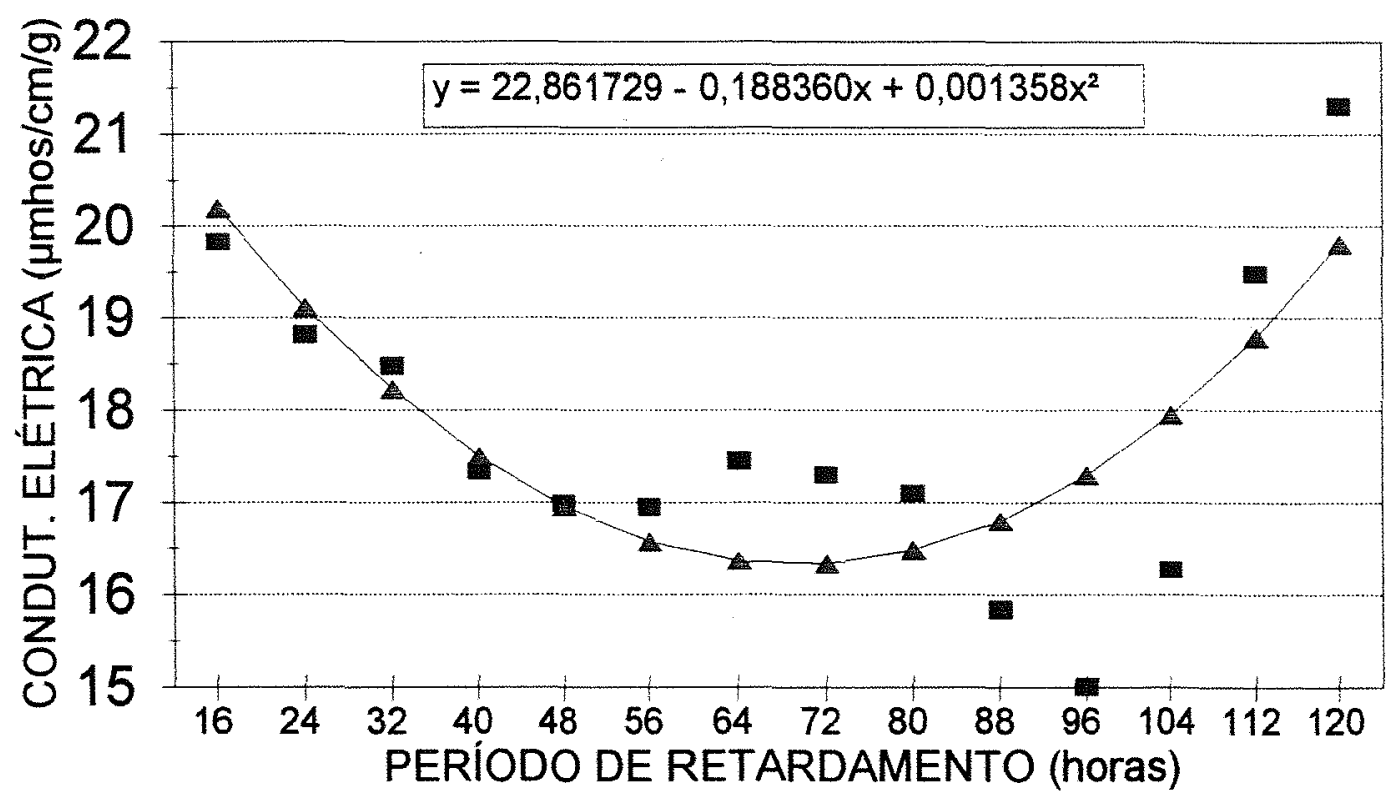

PONTOS OBSERVADOS PONTOS ESTIMADOS PELAEQUAÇÃO

Figura 7. Gráfico dos resultados do teste de condutividade elétrica na terceira época (12 meses): dados médios observados e estimados pela equação de regressão quadrática.

Todas apresentam ponto de inflexão da curva em torno daquele correspondente ao tempo de 72 horas de retardamento de secagem. Igualmente às considerações feitas quanto ao teste de condutividade elétrica na segunda época (Figura 2), a tendência é lógica a partir deste ponto, e inesperada antes dele.

Quanto ao teste de condutividade elétrica, os resultados apresentados na Tabela 12 e representados na Figura 7, agora já sob $R^{2}$ mais elevado $(0,601)$, reforçam ainda mais as hipóteses levantadas na discussão dos dados do teste na segunda época. 
Porém, em vista das tendências semelhantes reveladas pelos testes de germinação e de frio, igualmente significativas e sob $R^{2}$ de 0,710 e 0,458 respectivamente, outra hipótese pode ser apresentada, relacionando efeitos latentes positivos sobre a qualidade fisiológica das sementes que ocorreram desde o início do período de retardamento e em intensidade crescente até por volta de 72 horas de retardamento, com a sintese de ácido giberélico, indutor da enzima $\alpha$-amilase na camada de aleurona, fenômeno citado por Simon (1984) em sementes de trigo com teor de água ao redor de $25 \%$.

Assim teriamos um período promotor da qualidade fisiológica até por volta de 72 horas de retardamento, momento em que, fatores de deterioração passariam a ser dominantes, concorrendo então para perda de vigor, como pode ser verificado nas Figuras 5 e 6.

Tais hipóteses aqui levantadas:

a) existência de período necessário ao término da maturação das sementes ainda não fisiologicamente maduras, no sabugo;

b) existência de mecanismos de reparação e/ou organização do sistema de membranas celulares por curto período de tempo sob teores elevados de água;

c) ocorrência de síntese de ácido giberélico, indutor do processo de germinação, durante o início do período de retardamento de secagem; 
em conjunto ou isoladamente, poderiam estar relacionadas aos resultados encontrados por Pieta Filho \& Ellis (1992) em sementes de cevada e por Rao et al.(1991) em sementes de milheto, onde a máxima qualidade fisiológica ocorreu após o ponto de maturidade fisiológica.

Assim, novas pesquisas devem ser conduzidas visando esclarecer o comportamento fisiológico de sementes de milho a partir do ponto de maturidade fisiológica, associado ao estudo de atividades bioquímicas e de estruturas de membranas celulares, que procurem explicar parte dos resultados aqui apresentados, uma vez que a metodologia adotada não permitiu confrontações entre máxima qualidade, maturidade e momento de paralisação do fluxo de matéria seca para as sementes.

Finalizando, as condições do ar ambiente durante o período de retardamento considerado, sob umidades relativas e temperaturas relativamente baixas, não favoreceram a atividade metabólica das sementes, não sendo provável nestas condições, a ocorrência de efeitos negativos severos sobre a qualidade fisiológica das sementes. 


\section{CONCLUSÕES}

Considerando as condições moderadas de temperatura e de umidade relativa do ar presentes no presente estudo, o retardamento de até 120 horas ao início do processo de secagem artificial do milho em espiga, não promove efeitos prejudiciais à qualidade fisiológica das sementes, por até 6 meses de armazenamento. 


\section{REFERÊNCIAS BIBLIOGRÁFICAS}

ABDUL-BAKI, A. A. Bioquemical aspects of seed vigor. HortScience, v.15, n.6, p. $765-771,1980$.

ABDUL-BAKI, A. A.; ANDERSON, J. D. Physiological and biochemical deterioration of seeds. In: KOSLOWSKI, T. T. (Ed) Seed biology. New York: Academic Press, 1972. v.2, cap. 4, p.283-315.

ANDERSON, J. D.; GUPTA, K. Nucleotide alterations during seed deterioration. In: McDONALD Jr., M. B.; NELSON, C. J. (Ed). Physiology of seed deterioration. Madison: CSSA, 1986. p.47-63. (CSSA Special Publication, 11).

ANDRIGUETO, J. R. Efeitos do retardamento da secagem da semente de trigo (Triticum aestivum L.) sobre sua qualidade fisiológica. Pelotas, 1975. 73p. Dissertação (Mestrado) - Universidade Federal de Pelotas. 
BORBA, C. S. ; ANDREOLI, C. ; ANDRADE, R. V. de ; AZEVEDO, J. T. de. Maturidade fisiológica de sementes do híbrido simples BR 201 fêmea de milho (Zea mays L.) produzidas no inverno. Revista Brasileira de Sementes, v.17, n.1, p.129-132, $1995 a$.

BORBA, C. S. ; ANDREOLI, C. ; ANDRADE, R. V. de ; AZEVEDO, J. T. de ; OLIVEIRA, A. C. de. Retardamento da secagem e seu efeito na qualidade fisiológica de milho (Zea mays L.). Informativo ABRATES, v.5, n.2, p.54, 1995b.

BRASIL. Ministério da Agricultura e Reforma Agrária. Regras para análise de sementes. Brasília: MARA, SNAD, LANARV, 1992. 365p.

CARVALHO, M. L. M. de. Refrigeração e qualidade de sementes de milho armazenadas em pilhas com diferentes embalagens. Piracicaba, 1992. 98p. Tese (Doutorado) - Escola Superior de Agricultura "Luiz de Queiroz", Universidade de São Paulo.

CARVALHO, N. M. de ; NAKAGAWA, J. Sementes: ciência, tecnologia e produção. 2. ed. Campinas: Fundação Cargill, 1983. 429p.

CERQUEIRA, W. P. ; POPINIGIS, F. ; PESKE, S. T. ; SILVEIRA JÚNIOR, P. Retardamento da secagem de semente de soja (Glycine max. L. Merrill). Revista Brasileira de Armazenamento, v.4, n.2, p.56-63, 1979. 
CICERO, S.M.; VIEIRA, R.D. Teste de frio. In: VIEIRA, R.D.: CARVALHO, N.M. (Coord). Testes de vigor em sementes. Jaboticabal: FUNEP, 1994. p.151-164.

CICERO, S. M. ; ChAMMA, H. M. C. P. ; NOVEMBRE, A. D. L. C. ; MORAES, M. H. D. Tratamento fungicida e qualidade de sementes de milho. Piracicaba: ESALQ, Departamento de Agricultura, 1991. 41p. (Relatório Técnico).

DAYNARD, T. B.; DUNCAN, W. G. The black layer and grain maturity in corn. Crop Science, v.9, n.4, p.473-476, 1969.

DELOUCHE, J. C. Determinants of seed quality. In: SHORT COURSE FOR SEEDSMEN, Mississipi State, 1971. Proceedings. Mississipi State: Mississipi State University, 1971. v. 4, p.53-68.

DELOUCHE, J. C. Seed deterioration: notes on seed deterioration. Mississipi: Mississipi State University, 1972. 20p.

DELOUCHE, J. C. ; MATHEES, R.K. ; DOUGHERTY, G. M. ; BOYD, A. H. Storage of seed in sub-tropical and tropical regions. Seed Science and Technology, v.1, p.671-700, 1973.

ELLIS, R. H.; ROBERTS, E. H. Improved equations for the prediction of seed longevity. Annals of Botany, v. 45, p.13-30, 1980. 
FRANÇA NETO, J. B.; COSTA, N. P.; HENNING, A. A.; KRZYZANOWSKI, F. C.; PEREIRA, L. A. Efeito do retardamento do início de secagem sobre a qualidade de semente de soja. In: EMPRESA BRASILEIRA DE PESQUISA AGROPECUÁRIA. Centro Nacional de Pesquisa de Soja. Resultados de Pesquisa de Soja 1983/84. Londrina, 1984. p.101-104.

FRATIN, P. Comparação entre métodos para a avaliação da qualidade fisiológica de sementes de milho (Zea mays L.). Piracicaba, 1987. 191p. Dissertação (Mestrado) - Escola Superior de Agricultura "Luiz de Queiroz", Universidade de São Paulo.

GOMES, F. P. Curso de estatística experimental. 13. ed. São Paulo: Nobel, 1990. 468p.

GRABE, D. F. Measurement of seed vigor. Journal of Seed Technology, v.1, n.2, p.18-31, 1976.

GREGG, B. R. ; FAGUNDES, S. R. Condições para armazenamento de sementes. Brasília: AGIPLAN, 1977. 362p.

HERTER, U.; BURRIS, J.S. Changes in moisture, temperature, and quality of corn seed during high-temperature drying. Canadian Journal of Plant Science, v.69, n.3, p.749-761, 1989.

HUNTER, J. L.; TEKRONY, D. M.; MILES, D. F.; EGLI, D. B. Corn seed maturity indicators and their relationship to uptake of carbon-14 assimilate. Crop Science, v.31, p.1309-1313, 1991. 
KOCH, E. F. A. ; CASTELLANI, R. F. ; MORAES, M. H. D. ; ZAMBON, S. Avaliação de eficiência de fungicidas no tratamento de sementes de milho. Informativo ABRATES, v.5, n.2, p.97, 1995.

MAGUIRE, D. J. Speed of germination - aid in selection and evaluation for seedling emergence and vigor. Crop Science, v.2, n.2, p.176-177, 1962.

MARCOS FILHO, J. Teste de envelhecimento acelerado. In: VIEIRA, R.D; CARVALHO, N.M. (Coord). Testes de vigor em sementes. Jaboticabal: FUNEP, 1994. p.133-149.

MARCOS FILHO, J. ; CICERO, S. M. ; SILVA, W. R. da. Avaliação da qualidade das sementes. Piracicaba: FEALQ, 1987. 230p.

MARTINELLI, R. R. Efeitos do retardamento na secagem da semente de sorgo sacarino sobre sua qualidade fisiológica. Pelotas, 1985. 56p. Dissertação (Mestrado) - Universidade Federal de Pelotas.

MATTHES, R. K.; WELCH, G. B.; DELOUCHE, J. C.; DOUGHERTY, G. M. Drying, processing and storage of corn seed in tropical and subtropical regions. St. Joseph: ASAE, 1969. 28p. (ASAE Paper, 69577).

MCDONALD Jr., M. B. A review and evaluation of seed vigor testes. Proceedings of the Association of Official Seed Analysts, n.65, p.109139, 1975. 
McGEE, D. C. Symposium: Deterioration mechanisms in seeds. Introduction. Phytopatology, v.73, n.2, p.314-317, 1973.

MENTEM, J. O. M. Primeira semana de atualização em patologia de sementes. Piracicaba: FEALQ, 1988. 76p.

MORAES, M. H. D. ; CASTELLANI, R. F. ; LEITE, O. C. M. Avaliação da eficiência de fungicidas no tratamento de sementes de milho. Informativo ABRATES, v.5, n.2, p.98, 1995.

MUIR, W. E. Temperature and miosture in grain storage. In: SINHA, R.N.; MUIR, W.E. (Ed.). Grain storage: part of a system. Westpost: Connecticut, 1973, p.49-70.

MUÑOZ, G. S. ; ARBOLEDA, R. F. Influencia de la epoca de cosecha y del retardo al secamiento en la germinacion de la semilla de maiz (Zea mays L.). Informativo del Maiz, n.16, p.15, nov. 1976.

PEREIRA, O. A. P. Tratamento de sementes de milho. In: SIMPÓSIO BRASILEIRO DE PATOLOGIA DE SEMENTES, 2., Campinas, 1986. Palestras. Campinas: Fundação Cargill, 1986. p.145-148.

PIETA FILHO, C.; ELLIS, R. H. The development of seed quality in spring barley in four environments. II. Field emergence and seedling size. Seed Science Research, v.1, p.179-185, 1991. 
PIETA FILHO, C.; ELLIS, R. H. A máxima qualidade des sementes de cereais. Agropecuária Catarinense, v.5, n.1, p.27-29, 1992.

PINTO, N. F. J. A. Tratamento de sementes. Sete Lagoas: Empresa Brasileira de Pesquisa Agropecuária, Centro Nacional de Pesquisa de Milho e Sorgo, 1991. 10p.

POPINIGIS, F. Vigor de sementes: curso de produção de sementes. Piracicaba: ESALQ, 1975. 20p.

POPINIGIS, F. Fisiologia da semente. Brasilia: AGIPLAN, 1977. 289p.

RAO, N. K.; RAO, S. A.; MENGESHA, M. H.; ELLIS, R. H. Longevity of pearl millet (Pennisetum glaucum) seeds harvested at different stages of maturity. Annals of Applied Biology, v.1, p.97-103, 1991.

RASYAD, D. A.; VAN SANFORD, D.A.; TEKRONY, D. M. Changes in seed viability and vigour during wheat seed maturation. Seed Science and Technology, v.18, n.2, p.259-267, 1990.

ROBERTS, E. H. Loss of viability: ultrastructural and physiological aspects. Seed Science and Technology, v.1, p.529-545, 1973.

ROBERTS, E. H. Quantifying seed deterioration. In: MCDONALD Jr., M. B.; NELSON, C. J. (Ed.). Physiology of seed deterioration. Madison: CSSA, 1986. p.101-123. (CSSA Special Publication, 11). 
ROOS, E. E. Precepts of successsfull seed storage. In: McDONALD Jr., M. B.; NELSON, C. J. (Ed.) Physiology of seed deterioration. Madison: CSSA, 1986. p.1-25. (CSSA Special Publication, 11).

RUSH, M. A. P. Efeitos do retardamento da colheita e da secagem sobre a qualidade fisiológica de sementes de soja (Glycine max L. Merrill), cv. IAC8. Jaboticabal, 1985. 76p. Dissertação (Mestrado) - Faculdade de Ciências Agrárias e Veterinárias, Universidade Estadual Paulista Julio de Mesquita Filho.

SIMON, E. W. Early events in germination. In: MURRAY, D. R. (Ed.). Seed physiology. Sydnei: Academic Press, 1984. v. 2, p.77-115: Germination and reserve mobilization.

STEELE, J. L. ; SAUL, R. A. ; HUKILL, W. V. Deterioration of shelled corn as measured by carbon dioxide production. Transactions of the ASAE, v.12, n.5, p.685-689, 1969.

TAO, K. J. Factors causing variations in the condutivity test for soybeans seeds. Journal of Seed Technology, v.3, n.1, p.10-18, 1978.

TOLEDO, F. F. de ; MARCOS FILHO, J. Manual das sementes: tecnologia da produção. São Paulo: Agronômica Ceres, 1977. 224p.

TOLEDO, F. F. de. Tecnologia de sementes. In: PATERNIANI, E. Melhoramento e produção do milho no Brasil. Piracicaba: ESALQ, 1978. p.571-619. 
VALLE, J. C. G. Efeitos do retardamento de secagem de sementes de arroz Bluebelle (Oryza sativa L.) sobre sua qualidade fisiológica. Pelotas, 1978. 56p. Dissertação (Mestrado) - Universidade Federal de Pelotas.

VILLELA, F. A. Efeitos da secagem intermitente sobre a qualidade de sementes de milho. Piracicaba, 1991. 104p. Tese (Doutorado) - Escola Superior de Agricultura "Luiz de Queiroz", Universidade de São Paulo.

WELCH, G. B.; DELOUCHE, J. C. Seed processing and storage facilities for tropical areas. St. Joseph: ASAE, 1967. 20p. (ASAE Paper, 62-318).

WOODSTOCK, L. W. Physiological and biochemical tests for seed vigor. Seed Science and Technology, v.1, p.127-157, 1973. 